\title{
Novel pH-sensitive zinc phthalocyanine assembled with albumin for tumor targeting and treatment
}

This article was published in the following Dove Press journal:

International Journal of Nanomedicine

\author{
Ying Wang ${ }^{1,2}$ \\ Ke Zheng' \\ Guangshan Xuan' \\ Mingdong Huang ${ }^{3}$ \\ Jinping $\mathrm{Xue}^{3}$
}

'College of Chemical Engineering, Qingdao University of Science and Technology, Qingdao, Shandong, China; ${ }^{2}$ Key Lab of Inorganic Synthetic and Applied Chemistry, State Key Lab Base of Eco-Chemical Engineering, College of Chemistry and Molecular Engineering, Qingdao University of Science and Technology, Qingdao, Shandong, China; ${ }^{3}$ College of

Chemistry, Fuzhou University, Fuzhou, Fujian, China
Correspondence: Ke Zheng College of Chemical Engineering, Qingdao University of Science and Technology, 53 Zhengzhou Road, Qingdao, Shandong 266042, China $\mathrm{Tel}+8613210185127$ Email zhengke_qust@I63.com
Purpose: Zinc phthalocyanine ( $\mathrm{ZnPc}$ ) has been applied widely in photodynamic therapy (PDT) with high ROS-production capacity and intense absorption in the near-infrared region. However, weak tumor targeting and the aggregation tendency of ZnPc seriously affect the therapeutic effect of PDT. Therefore, overcoming the aggregation of $\mathrm{ZnPc}$ and enhancing its antitumor effect were the purpose of this study.

Methods: In this study, we first found that the aggregation behaviors of the photosensitizer $\mathrm{ZnPc}(\mathrm{TAP})_{4}$, ZnPc substituted by tertiary amine groups, were regulated finely by $\mathrm{pH}$ and that $\mathrm{ZnPc}(\mathrm{TAP})_{4}$ could be disaggregated gradually as the $\mathrm{pH}$ descended. $\mathrm{ZnPc}(\mathrm{TAP})_{4}$ and human serum albumin (HSA) molecules were assembled into nanoparticles (NPs) for tumor targeting. Meanwhile, the chemotherapy drug paclitaxel (Ptx) was loaded into HSA NPs together with $\mathrm{ZnPc}(\mathrm{TAP})_{4}$ for dual antitumor effects. HSA NPs loading both $\mathrm{ZnPc}(\mathrm{TAP})_{4}$ and Ptx (NP$\mathrm{ZnPc}[\mathrm{TAP}]_{4}-\mathrm{Ptx}$ ) were characterized by particle size and in vitro release. Cytotoxicity, subcellular localization, tumor targeting, and anticancer effect in vivo were investigated respectively.

Results: We found that NP-ZnPc(TAP) - -Ptx had good stability with qualifying particle size. Interestingly, $\mathrm{ZnPc}(\mathrm{TAP})_{4}$ was released from the NPs and the photodynamic activity enhanced in the acidic environment of tumor. In addition, $\mathrm{NP}-\mathrm{ZnPc}(\mathrm{TAP})_{4}-\mathrm{Ptx}$ had prominent cytotoxicity and time-dependent subcellular localization characteristics. Through a three-dimensional animal imaging system, $\mathrm{NP}-\mathrm{ZnPc}(\mathrm{TAP})_{4}-\mathrm{Ptx}$ showed much-enhanced tumor targeting in tumor-bearing mice. Above all, $\mathrm{NP}-\mathrm{ZnPc}(\mathrm{TAP})_{4}-\mathrm{Ptx}$ was demonstrated to have the synergistic anticancer effect of PDT and chemotherapy.

Conclusion: $\mathrm{NP}-\mathrm{ZnPc}(\mathrm{TAP})_{4}-\mathrm{Ptx}$ had enhanced tumor targeting for the $\mathrm{pH}$-sensitive property of $\mathrm{ZnPc}(\mathrm{TAP})_{4}$ and the transport function of HSA. NP-ZnPc(TAP) $)_{4}-\mathrm{Ptx}$ possessed a doubleanticancer effect through the combination of $\mathrm{ZnPc}(\mathrm{TAP})_{4}$ and Ptx. This drug-delivery system may also be used to carry chemotherapy drugs other than Ptx for improving antitumor effects.

Keywords: photodynamic therapy, drug-delivery system, controlled release, chemotherapy, antitumor activity, combination therapy

\section{Introduction}

Photodynamic therapy (PDT) has emerged as an effective and minimally invasive treatment method for tumor. ${ }^{1}$ Zinc phthalocyanine (ZnPc), known as a second-generation photosensitizer, has excellent photochemical properties with high ROS production ability and intense absorption in the near-infrared region, and gathers much attention for PDT nowadays. ${ }^{2}$ However, its weak tumor targeting and aggregation tendency ${ }^{3}$ seriously affect PDT's therapeutic effect.

Drug-delivery systems enable drugs to be more efficient. ${ }^{4}$ Nanodrug carriers are widely applied to deliver $\mathrm{ZnPc}$ to tumor tissue for the enhanced permeability and retention effect. ${ }^{5}$ A number of drug carriers have emerged, including polymeric 
nanoparticles (NPs), nanocapsules, liposomes, micelles, gold NPs, ceramic NPs, magnetic NPs, and dendrimers. ${ }^{6}$ However, most of these drug carriers are exogenous materials for humans and may have some side effects. Human serum albumin (HSA) is one kind of natural polymer material with atoxic and metabolizable characteristics, and is an excellent drug-carrier material. ${ }^{7}$ The US Food and Drug Administration has approved Abraxane (NP albumin-bound paclitaxel) for treating metastatic breast cancer. Abraxane is prepared by high-shear homogenization, which can disrupt disulfide bonds and form new disulfide bonds. ${ }^{7}$

The aggregation property of $\mathrm{ZnPc}$ causes not only fluorescence quenching but also a significantly reduced ROS-production rate. Surfactant Cremophor EL can make phthalocyanines disaggregated, but its application is limited by its side effects of hypersensitivity reactions. ${ }^{8}$ Bulky substituents can inhibit aggregation of ZnPc only in organic solvents, rather than water solution. ${ }^{9}$ Some ion substituents (eg, sulfo-, carboxy-, and quaternary ammonium salt groups $)^{10-12}$ can overcome the aggregation of phthalocyanines based on electrostatic interaction in water solution. As such, $\mathrm{ZnPc}$ modified by ionic groups shows great application prospects for PDT.

In our current study, the aggregation behavior of substituted $\mathrm{ZnPc}$ containing 12 tertiary amine groups, 2,9,16,23tetrakis[2,4,6-tris( $N, N$-dimethylaminomethyl)phenoxy] $\mathrm{ZnPc}(\mathrm{TAP})_{4}$, was first found to be regulated by $\mathrm{pH}$ in solution. $\mathrm{ZnPc}(\mathrm{TAP})_{4}$ was loaded into HSA NPs prepared by sulfhydryl self-assembly together with the chemotherapeutic anticancer drug paclitaxel (Ptx) to obtain the complex $\mathrm{NP}-\mathrm{ZnPc}(\mathrm{TAP})_{4}-\mathrm{Ptx}$. Particle size and stability of NP$\mathrm{ZnPc}(\mathrm{TAP})_{4}-\mathrm{Ptx}$ were characterized. NP-ZnPc(TAP) $)_{4}^{-}$ Ptx was demonstrated to have $\mathrm{pH}$-sensitive properties for $\mathrm{ZnPc}(\mathrm{TAP})_{4}$ release. $\mathrm{NP}-\mathrm{ZnPc}(\mathrm{TAP})_{4}-\mathrm{Ptx}$ was found to have a potent cytotoxicity effect in vitro. Interestingly, $\mathrm{NP}-\mathrm{ZnPc}(\mathrm{TAP})_{4}-\mathrm{Ptx}$ had different subcellular localization following extended time. H22 tumor-bearing Kunming mice were established and tumor-targeting experiments carried using a three-dimensional (3D) imaging system. It was demonstrated that $\mathrm{NP}-\mathrm{ZnPc}(\mathrm{TAP})_{4}-\mathrm{Ptx}$ had an enhanced tumor targeting effect over $\mathrm{ZnPc}(\mathrm{TAP})_{4}$ through HSA-NP loading. Most of all, NP-ZnPc(TAP) - -Ptx showed a higher antitumor effect, which could be attributable to combined application of phototherapy and chemotherapy. This $\mathrm{pH}-$ sensitive drug-delivery system loading $\mathrm{ZnPc}(\mathrm{TAP})_{4}$ may be applied to simultaneous delivery of other chemotherapy drugs for synergistic anticancer purposes.

\section{Methods}

\section{Materials}

$\mathrm{ZnPc}(\mathrm{TAP})_{4}$ (Figure 1A) was synthesized and characterized as per a previous method reported by our group. ${ }^{13} \mathrm{Ptx}$ was purchased from DKY Technology (Wuhan, China). HSA was purchased from Shanghai RAAS Blood Products (Shanghai, China). Non-small-cell lung carcinoma cells (H1299) were obtained from the American Type Culture Collection (ATCC) (Manassas, VA, USA). Mouse H22 hepatoma cells were purchased from the Cell Bank of the Chinese Academy of Sciences (Shanghai, China). RPMI 1640 medium and FBS used for cell culture were purchased from Thermo Fisher Scientific (Waltham, MA, USA). Other chemicals were purchased from either Sigma-Aldrich Co. (St Louis, MO, USA) or Sinopharm Chemical Reagent (Shanghai, China). Clean-level Kunming mice were purchased from Shanghai SLAC Laboratory Animal, Chinese Academy of Sciences (Shanghai, China).

\section{Ultraviolet-visible and fluorescence spectra of $\mathrm{ZnPc}(\mathrm{TAP})_{4}$}

PBS $(180 \mu \mathrm{L}, \mathrm{pH} 6.0,6.2,6.4,6.8,7.0,7.2,7.4,7.6,8.0)$ was added to 96-well plates that contained $20 \mu \mathrm{L} \mathrm{ZnPc(TAP)})_{4}$ (50 $\mu \mathrm{M}$ in ethanol solution). Ultraviolet-visible and fluorescence spectra (excitation wavelength $610 \mathrm{~nm}$ ) of the mixed solution were detected by a microplate reader (BioTek Instruments, Winooski, VT, USA).

\section{ROS measurement of $\mathrm{ZnPc}(\mathrm{TAP})_{4}$ with different $\mathrm{pH}$}

PBS $(198 \mu \mathrm{L}, \mathrm{pH} 6.0,6.2,6.4,6.8,7.0,7.2,7.4,7.6,8.0)$ containing $\mathrm{ZnPc}(\mathrm{TAP})_{4} 5 \mu \mathrm{M}$ was added to $96-$ well plates. Then, $2 \mu \mathrm{L}$ dimethyl sulfoxide (DMSO) solution of 2,7dichlorodihydrofluorescein diacetate (DCFH-DA; $500 \mu \mathrm{M}$ ) was added to the PBS with different $\mathrm{pH}$. Mixed solutions were irradiated using an LED light source $\left(20 \mathrm{~mW} / \mathrm{cm}^{2}\right)$ for 5 minutes in total. Fluorescence maximum-emission intensity was detected by a microplate reader (BioTek Instruments) with excitation wavelength at $480 \mathrm{~nm}$ every 1 minute during the whole 5 minutes.

\section{Preparation of $\mathrm{NP}-\mathrm{ZnPc}(\mathrm{TAP})_{4}-\mathrm{Ptx}$}

$\beta$-Mercaptoethanol (2 $\mu \mathrm{L})$, PBS (750 $\mu \mathrm{L}, \mathrm{pH} 8)$, and HSA solution $(250 \mu \mathrm{L}, 200 \mathrm{mg} / \mathrm{mL})$ were mixed together. After being stirred for 15 minutes, the solution was diluted using $1 \mathrm{~mL}$ PBS ( $\mathrm{pH}$ 8). Then, $\mathrm{ZnPc}(\mathrm{TAP})_{4}$ ethanol solution $(0.5 \mathrm{~mL}, 7.6 \mathrm{mM})$ was added to the solution. After incubation for 5 minutes, Ptx DMSO solution (15.2 mM, $100 \mu \mathrm{L})$ was 
A
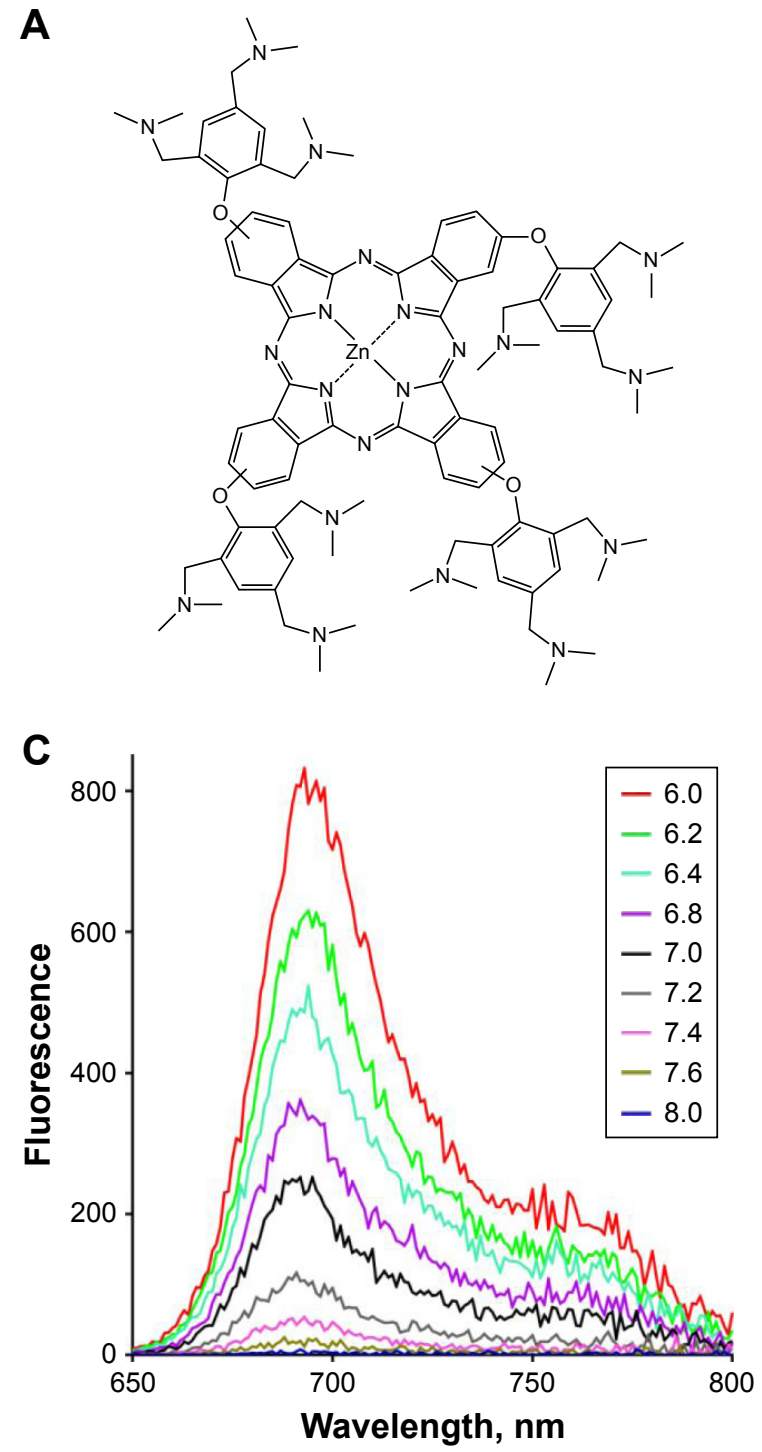
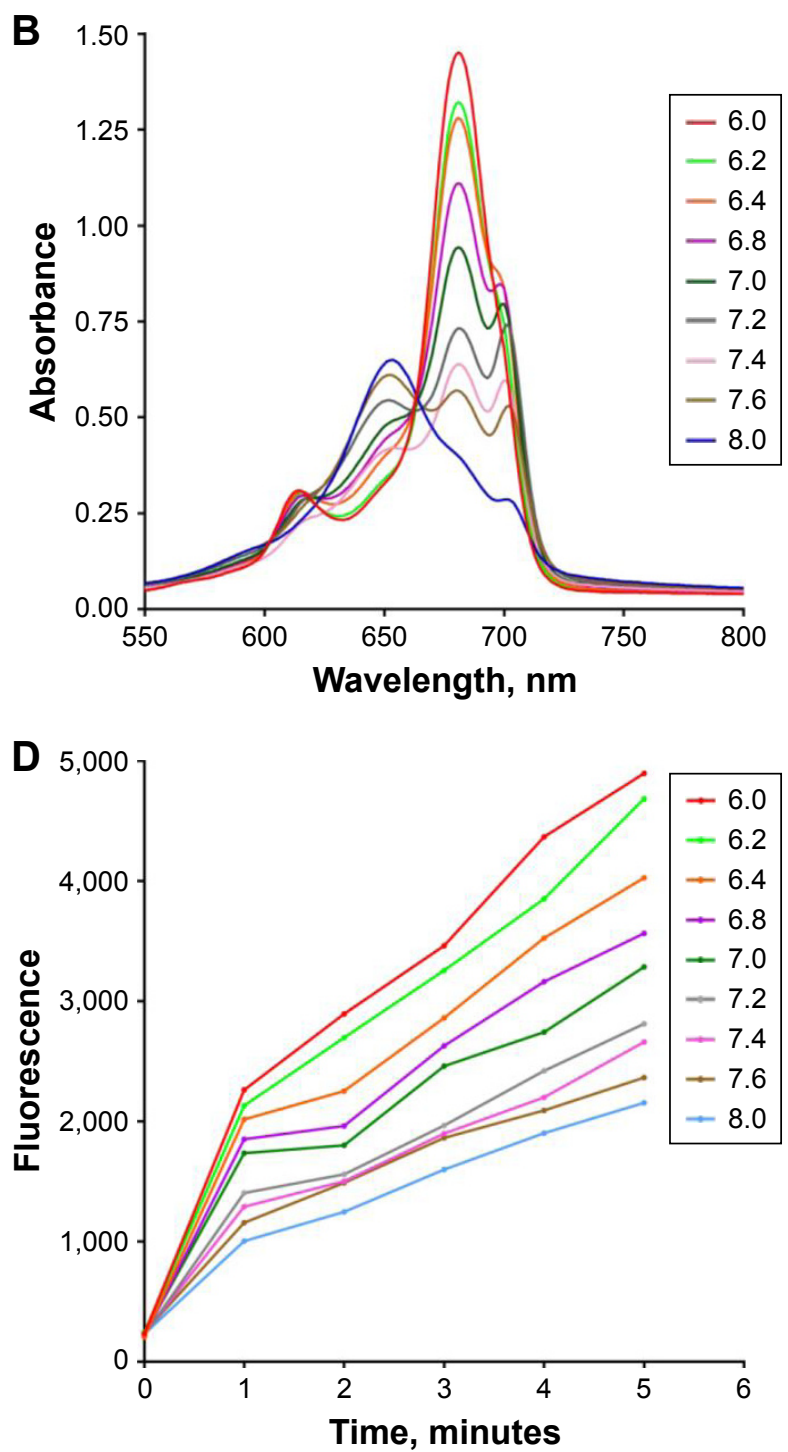

Figure I (A) Structure of $\mathrm{ZnPc}(\mathrm{TAP})_{4}$, which consists of $\mathrm{I} 2$ tertiary amine groups. (B and C) Electronic spectra of $\mathrm{ZnPc}(\mathrm{TAP})_{4}$ in $\mathrm{PBS}$ with different $\mathrm{pH}(6.0,6.2,6.4,6.8,7.0$, 7.2, 7.4, 7.6, and 8.0). (B) The ultraviolet-visible spectrum of $\mathrm{ZnPc}(\mathrm{TAP})_{4}(5 \mu \mathrm{M})$ was regulated by $\mathrm{PH}$ in the solution. There were different forms of $\mathrm{ZnPc}(\mathrm{TAP})_{4}$ at different $\mathrm{pH}$, including $\mathrm{H}$-type aggregate, J-type aggregate, and monomer form. (C) Fluorescence spectra of $\mathrm{ZnPc}(\mathrm{TAP})_{4}(5 \mu \mathrm{M})$ were variable at different $\mathrm{pH}$. Fluorescence intensity was enhanced with $\mathrm{pH}$ decrease. (D) Fluorescence of DCFH-DA (final concentration $5 \mu \mathrm{M}$ ) was activated by ROS generated by $\mathrm{ZnPc}(\mathrm{TAP})_{4}(5 \mu \mathrm{M})$ after illumination for different times. $\mathrm{ZnPc}(\mathrm{TAP})_{4}$ had increased $\mathrm{ROS}$ production following $\mathrm{pH}$ decrease.

Abbreviations: ZnPc, zinc phthalocyanine; DCFH-DA, 2,7-dichlorodihydrofluorescein diacetate.

also added to the solution and mixed for another 5 minutes. Finally, another $2 \mathrm{~mL}$ ethanol was added dropwise into the solution. After being stirred for 4 hours, PBS ( $5 \mathrm{~mL}, \mathrm{pH} 8)$ was added to the reaction solution and the solution dialyzed to PBS (pH 7.4) by dialysis bag with molecular-weight cutoff $8-10 \mathrm{kDa}$. After the dialysis, the solution was centrifuged at 12,000 rpm for 30 minutes and $\mathrm{NP}-\mathrm{ZnPc}(\mathrm{TAP})_{4}-\mathrm{Ptx}$ precipitated. $\mathrm{NP}-\mathrm{ZnPc}(\mathrm{TAP})_{4}-\mathrm{Ptx}$ was resuspended three times for purification. The $\mathrm{NP}-\mathrm{ZnPc}(\mathrm{TAP})_{4}-\mathrm{Ptx}$ solution was then applied to a diethylaminoethyl anion-exchange (DEAE) column (GE Healthcare UK Ltd, Little Chalfont,
UK) for further purification. NP-ZnPc(TAP) $)_{4}$ or NP-Ptx was prepared by the same method, except for the addition of Ptx or $\mathrm{ZnPc}(\mathrm{TAP})_{4}$, respectively.

\section{Characterization of $\mathrm{NP}-\mathrm{ZnPc}(\mathrm{TAP})_{4}-\mathrm{Ptx}$}

Ultraviolet-visible spectra of NP-ZnPc(TAP) $)_{4}-\mathrm{Ptx}$ and NP$\mathrm{ZnPc}(\mathrm{TAP})_{4}$ were monitored by the microplate reader. Singletoxygen quantum yields $\left(\Phi_{\Delta}\right)$ of $\mathrm{NP}-\mathrm{ZnPc}(\mathrm{TAP})_{4}-\mathrm{Ptx}$ and $\mathrm{ZnPc}(\mathrm{TAP})_{4}$ were detected using 1,3-diphenylisobenzofuran as chemical quencher. Particle size and potential were characterized with a Malvern Zetasizer ZS (Malvern Instruments, 
Malvern, UK). Concentrations of HSA, ZnPc(TAP), and Ptx in NP-ZnPc(TAP) $)_{4}$-Ptx were detected for defining the coupling ratio. $\mathrm{NP}-\mathrm{ZnPc}(\mathrm{TAP})_{4}$-Ptx was degraded by lysate containing $2 \% \mathrm{SDS}(\mathrm{w}: \mathrm{v})$ and $0.1 \mathrm{M} \mathrm{NaOH}$. The concentration of HSA in the lysate was checked with a BCA proteinassay kit (BioTek Instruments). Ptx concentration was detected using HPLC by establishing a calibration curve for Ptx. Then, DMSO was added to the lysate to a final concentration of $90 \%$. $\mathrm{ZnPc}(\mathrm{TAP})_{4}$ concentration in the $90 \% \mathrm{DMSO}$ solution was quantified using its fluorescence quantitative calibration curve (excitation wavelength $610 \mathrm{~nm}$ ).

\section{Drug-release curve}

$\mathrm{NP}-\mathrm{ZnPc}(\mathrm{TAP})_{4}-\mathrm{Ptx}$ solution $\left(5 \mathrm{~mL}\right.$, containing $\mathrm{ZnPc}[\mathrm{TAP}]_{4}$ $50 \mu \mathrm{M}$ ) was stored in PBS with pH 7.4, 7.2, 7.0, 6,8, 6.4, or 6.2. The coupling ratio of Ptx:HSA was detected by the aforementioned methods. After the solution had been centrifuged for 30 minutes at 12,000 rpm, supernatant was removed and the coupling ratio of precipitate for $\mathrm{ZnPc}(\mathrm{TAP})_{4}: \mathrm{Ptx}: \mathrm{HSA}$ detected by the same method. The coupling ratio of $\mathrm{NP}-\mathrm{ZnPc}(\mathrm{TAP})_{4}-\mathrm{Ptx}$ at $\mathrm{pH} 7.4$ was monitored for 14 days.

\section{Cytotoxicity}

Non-small-cell lung cancer (H1299) cells were cultivated in the RPMI 1640 medium supplemented with 10\% FBS at $37^{\circ} \mathrm{C}$ in a humidified incubator with $5 \% \mathrm{CO}_{2}$ atmosphere. The viability of cells was determined by trypan-blue dye exclusion. Cells were maintained in the logarithmic phase with viability. After dissociation of the cells by trypsin, suspended cells were added to 96-well Costar plates, with 8,000 cells in each well. After cell attachment, $\mathrm{NP}-\mathrm{ZnPc}(\mathrm{TAP})_{4}-\mathrm{Ptx}$, $\mathrm{NP}-\mathrm{ZnPc}(\mathrm{TAP})_{4}$, or $\mathrm{ZnPc}(\mathrm{TAP})_{4}$ was added to the wells, and final concentrations of $\mathrm{ZnPc}(\mathrm{TAP})_{4}$ in the wells were $0.5 \mu \mathrm{M}$, $1 \mu \mathrm{M}, 5 \mu \mathrm{M}, 10 \mu \mathrm{M}$, and $50 \mu \mathrm{M}$. After 24 hours, medium was replaced by fresh medium without samples. Then, cells in the 96-well plates were illuminated by an LED light source (680 nm, $100 \mathrm{~mW}$, Sundynamic, Qingdao, China) with light fluence of $1.5 \mathrm{~J} / \mathrm{cm}^{2}$ for 1 minute. After 24 hours, viable cells were checked by MTT. Each experiment was repeated three times, with four replicates at each time point. Dark toxicity of cells was detected in the same way, just without illumination. The cytotoxicity of $\mathrm{NP}-\mathrm{ZnPc}(\mathrm{TAP})_{4}-\mathrm{Ptx}$ and NP-Ptx with illumination was detected by the same method at Ptx concentrations of $0.3 \mu \mathrm{M}, 0.6 \mu \mathrm{M}, 3 \mu \mathrm{M}, 6 \mu \mathrm{M}$, $12 \mu \mathrm{M}$, and $30 \mu \mathrm{M}$.

\section{Cellular localization}

The suspended cells (H1299) were plated onto confocal chamber slides (Nest Biotechnology Wuxi, Jiangsu, China) at $37^{\circ} \mathrm{C}$ centigrade and incubated for 24 hours. Then, NP$\mathrm{ZnPc}(\mathrm{TAP})_{4}-\mathrm{Ptx}$ was added to the medium, and the final concentration of $\mathrm{ZnPc}(\mathrm{TAP})_{4}$ was $10 \mu \mathrm{M}$. After incubation for 30 minutes or 2 hours, adherent cells were washed with PBS to remove unbound NP-ZnPc(TAP) - $-\mathrm{Ptx}$ and then incubated in medium containing MitoTracker green $(40 \mathrm{nM})$ or LysoTracker ( $75 \mathrm{nM}$ ) for 30 minutes. Cells were then washed with PBS and incubated in fresh medium. Laser-scanning confocal microscopy (FluoView FV1000; Olympus Corporation, Tokyo, Japan) was used for cell imaging. The fluorescence of MitoTracker green, LysoTracker, or ZnPc(TAP) in the cells on the confocal chamber slides was excited by an argon-ion laser light (wavelength $488 \mathrm{~nm}, 550 \mathrm{~nm}$, or 633 $\mathrm{nm})$, while emitted fluorescence was filtered with barrier filters (420/30 nm, 590/30 nm, or 640-700 nm band pass). All parameters, including laser-line intensity, photometric gain, settings of photomultiplier tube, and filter attenuation, were kept constant throughout the entire imaging experiment. All images were analyzed with FluoView v2.1 software.

\section{Establishment of $\mathrm{H} 22$ tumor-bearing mouse model}

Male Kunming mice (4 weeks old and weighing 18-22 g) were purchased from Shanghai SLAC Laboratory Animal. Mouse H22 cells $\left(5 \times 10^{6}\right)$ were injected into the mice's abdominal cavities. After cultivation for 6 days, mice were executed by breaking the neck. Ascetic fluid was collected and cell quantity counted. Then, $\mathrm{H} 22$ cells $\left(2 \times 10^{6}\right)$ from the ascetic fluid in normal saline $(200 \mu \mathrm{L})$ were injected into the back. Typically, tumor volume reached around $50 \mathrm{~mm}^{3}$ in 5-7 days after inoculation, and the mouse model was established successfully. All animal experiments were approved by the Animal Care Committee of Qingdao University of Science and Technology, and all animal studies were performed in compliance with the guidelines of the committee.

\section{Fluorescence imaging in vivo}

The H22 tumor-bearing Kunming mice were randomly divided into two groups (five mice per group) with equivalent average starting tumor size $\left(50 \mathrm{~mm}^{3}\right)$ and body weight (23 g). NP-ZnPc(TAP) ${ }_{4}-\mathrm{Ptx}$ and $\mathrm{ZnPc}(\mathrm{TAP})_{4}$ (each sample contained $\left.\mathrm{ZnPc}[\mathrm{TAP}]_{4} 25 \mu \mathrm{mol} / \mathrm{L}\right)$ in normal saline solution were prepared and injected into $\mathrm{H} 22$ tumor-bearing Kunming mice via tail vein $\left(0.2 \mu \mathrm{mol} / \mathrm{kg} \mathrm{ZnPc}[\mathrm{TAP}]_{4}\right)$. Then, at 1 , 2, 4, 12, 24, and 48 hours, mice were anaesthetized with isoflurane and $\mathrm{NP}-\mathrm{ZnPc}(\mathrm{TAP})_{4}-\mathrm{Ptx}$ or $\mathrm{ZnPc}(\mathrm{TAP})_{4}$ fluorescence monitored by a fluorescence molecular tomography (FMT) 2500LX instrument (PerkinElmer Inc., Waltham, 
MA, USA). Throughout the experiment, all mice were kept in a dark room and light exposure avoided. $\mathrm{ZnPc}(\mathrm{TAP})_{4}$ solution $(0.2 \mu \mathrm{mol} / \mathrm{L})$ in PBS containing $5 \%$ Cremophor EL was used as a standard to calibrate the instrument for the quantification of $\mathrm{ZnPc}(\mathrm{TAP})_{4}$ concentration. Data collected were reconstructed by the software TrueQuant version 3.0 (PerkinElmer Inc.) to 3D and quantitative information was analyzed by creating regions of interest around the tumor sites after the subtraction of fluorescence background.

\section{Antitumor efficacy of $\mathrm{NP}-\mathrm{ZnPc}(\mathrm{TAP})_{4}-\mathrm{Ptx}$ in $\mathrm{H} 22$ tumor-bearing Kunming mice}

H22 tumor-bearing mice were randomly divided into three groups (ten mice per group) as described earlier. Every mouse had equivalent tumor volume $\left(50 \mathrm{~mm}^{3}\right)$ and weight $(23 \mathrm{~g})$. $\mathrm{NP}-\mathrm{ZnPc}(\mathrm{TAP})_{4}-\mathrm{Ptx}, \mathrm{NP}-\mathrm{ZnPc}(\mathrm{TAP})_{4}$, or $\mathrm{ZnPc}(\mathrm{TAP})_{4}$ solution in normal saline (each solution contained $25 \mu \mathrm{mol} / \mathrm{L}$ $\mathrm{ZnPc}[\mathrm{TAP}]_{4}$ ) was injected into the mice's via tail veins at a dose of $0.2 \mu \mathrm{mol} / \mathrm{kg} \mathrm{ZnPc}(\mathrm{TAP})_{4}$. All mice were fed in a dark room, and every 24 hours the tumor site was illuminated by a $680 \mathrm{~nm}$ light source (1 W, LumaCare Medical, Newport Beach, CA, USA) for 3 minutes to a light dose of $50 \mathrm{~J} / \mathrm{cm}^{2}$. PDT lasted for 7 days and tumor volume in every mouse measured each day by a caliper through an ellipsoid-volume formula: $\pi / 6 \times($ length $\times$ width $\times$ height $)$. The weight of mice was measured using an electronic scale on a daily basis.

\section{Statistical analysis}

All data represent group mean and SEM. The experimental data were analyzed using unpaired two-tailed Student's $t$-tests. Differences at the $95 \%$ confidence level $(P<0.05)$ were considered statistically significant.

\section{Results \\ Electronic spectra of $\mathrm{ZnPc}(\mathrm{TAP})_{4}$ regulated by solution $\mathrm{pH}$}

Ultraviolet-visible and fluorescence-emission spectra of $\mathrm{ZnPc}(\mathrm{TAP})_{4}$ were detected in PBS with different $\mathrm{pH}$ (6.0, $6.2,6.4,6.8,7.0,7.2,7.4,7.6,8.0)$. Figure 1B shows that $\mathrm{ZnPc}(\mathrm{TAP})_{4}$ had typical absorption peaks of phthalocyanine, while the peak shape was changed with different $\mathrm{pH}$. The maximum-absorption peak was at $680 \mathrm{~nm}$ (pH 6.0), which suggested a monomer form of $\mathrm{ZnPc}(\mathrm{TAP})_{4}$. The maximumabsorption peak gradually decreased following elevated $\mathrm{pH}$ and was blue-shifted to $653 \mathrm{~nm}$ when $\mathrm{pH}$ was raised to 8.0, which indicated $\mathrm{ZnPc}(\mathrm{TAP})_{4}$ aggregated gradually. It is noteworthy that the third peak at $700 \mathrm{~nm}$ rose from $\mathrm{pH} 6.8$ to 7.6. The double peaks (at $680 \mathrm{~nm}$ and $700 \mathrm{~nm}$ ) suggested that J-aggregation occurred among molecules of $\mathrm{ZnPc}(\mathrm{TAP})_{4}$. Figure $1 \mathrm{C}$ shows fluorescence-emission spectra with excitation wavelength $610 \mathrm{~nm}$. pH went decreased 8.0 to 6.0 , and fluorescence intensity was gradually enhanced. During just the two $\mathrm{pH}$ changes, fluorescence intensity increased more than 200 times from about 4 to 830 . Fluorescence quenching was caused by aggregation of molecules. Changes in ultraviolet-visible and fluorescence spectra exhibited a response sensitive to $\mathrm{pH}$.

\section{Higher ROS productivity following $\mathrm{pH}$ decrease}

DCFH-DA is a probe of ROS and can be transformed into 2,7-dichlorofluorescein (DCF) in the presence of ROS. Though DCFH-DA had no fluorescence properties, DCF fluorescence was excited at $485 \mathrm{~nm}$, and the fluorescence intensity was proportional to DCF concentration, so DCF fluorescence intensity was used to monitor ROS generation. Figure 1D shows that DCF fluorescence intensity was gradually enhanced as the illumination time was prolonged in all solutions with different $\mathrm{pH}$. At any point of illumination time, lower $\mathrm{pH}$ in $\mathrm{PBS}$ could generate stronger fluorescenceemission intensity of DCF, which suggested more ROS productivity through $\mathrm{ZnPc}(\mathrm{TAP})_{4}$ in an acidic environment.

\section{Preparation and characterization of $\mathrm{NP}-\mathrm{ZnPc}(\mathrm{TAP})_{4}-\mathrm{Ptx}$}

The method of sulfhydryl self-assembly was used for preparing HSA NPs. The disulfide bonds of HSA molecules were firstly cleaved by mercaptoethanol. HSA molecules were gathered by dehydration of ethanol and the free-sulfhydryl groups obtained further cross-linked to form HSA NPs. Through the hydrophobic interaction, $\mathrm{ZnPc}(\mathrm{TAP})_{4}$ and Ptx molecules were loaded into the HSA NPs. Ultravioletvisible spectra of NP-ZnPc(TAP) ${ }_{4}-\mathrm{Ptx}$ and $\mathrm{NP}-\mathrm{ZnPc}(\mathrm{TAP})_{4}$ (Figure S1) showed that both had maximum-absorption wavelength at $686 \mathrm{~nm}$ in PBS with $\mathrm{pH} 7.4$, which was different from that of $\mathrm{ZnPc}(\mathrm{TAP})_{4}$ at $\mathrm{pH} 7.4$ without $\mathrm{HSA}(650$ $\mathrm{nm}, 681 \mathrm{~nm}, 702 \mathrm{~nm})$. The difference suggested an interaction between $\mathrm{ZnPc}(\mathrm{TAP})_{4}$ and HSA. More detailed data of ultraviolet-visible and singlet-oxygen generation were shown in Table $\mathrm{S} 1$. The result indicated that $\mathrm{ZnPc}(\mathrm{TAP})_{4}$ and $\mathrm{NP}-\mathrm{ZnPc}(\mathrm{TAP})_{4}-\mathrm{Ptx} \Phi_{\Delta}$ increased with reduced $\mathrm{pH}$. The coupling ratio of $\mathrm{HSA}, \mathrm{ZnPc}(\mathrm{TAP})_{4}$, and $\mathrm{Ptx}$ in $\mathrm{NP}$ $\mathrm{ZnPc}(\mathrm{TAP})_{4}-\mathrm{Ptx}$ was about 1:3:1.8, which demonstrated $\mathrm{ZnPc}(\mathrm{TAP})_{4}$ and Ptx were successfully loaded into HSA NPs. Dynamic light-scattering measurement showed that the average diameter of NP-ZnPc(TAP) $)_{4}-\mathrm{Ptx}$ was $107 \mathrm{~nm}$ 
A

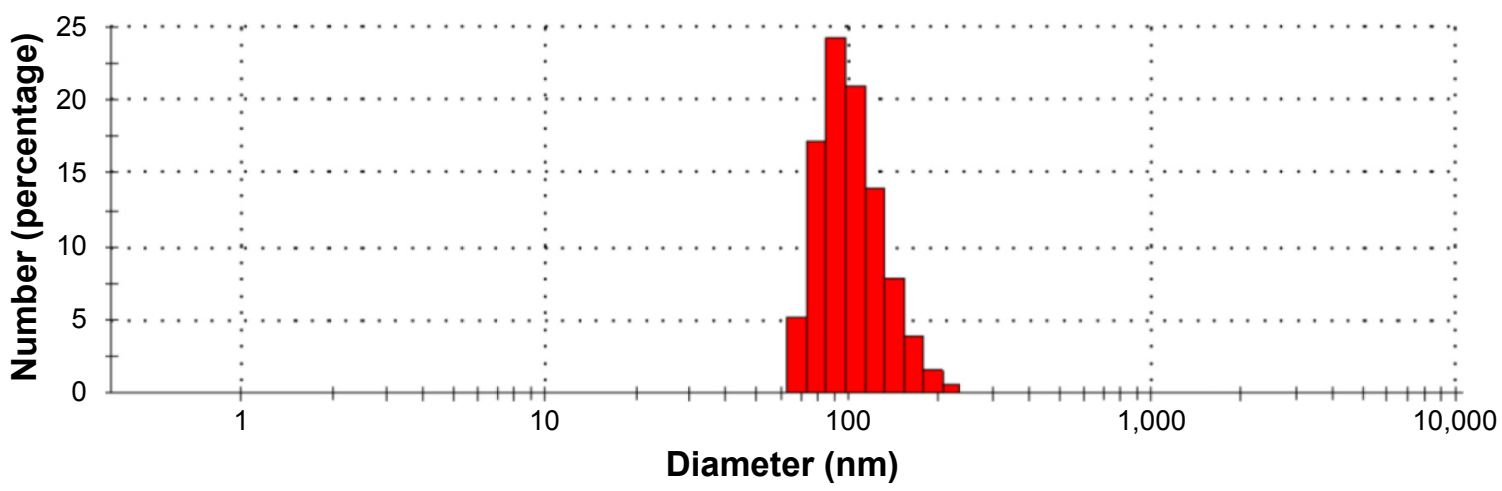

B

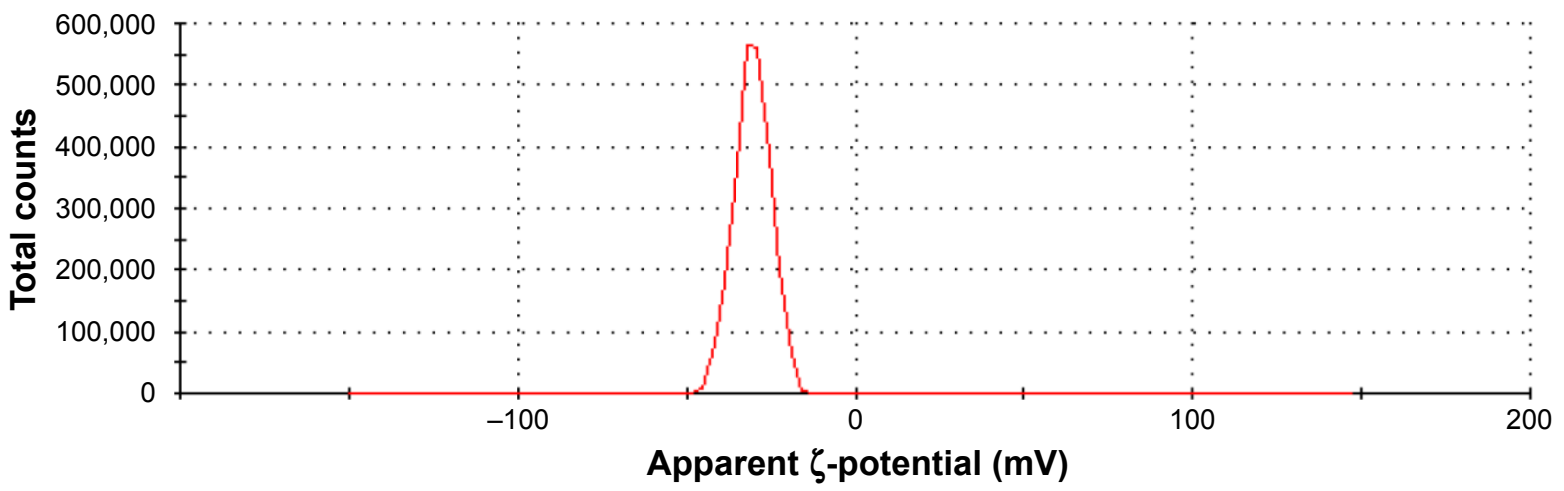

C

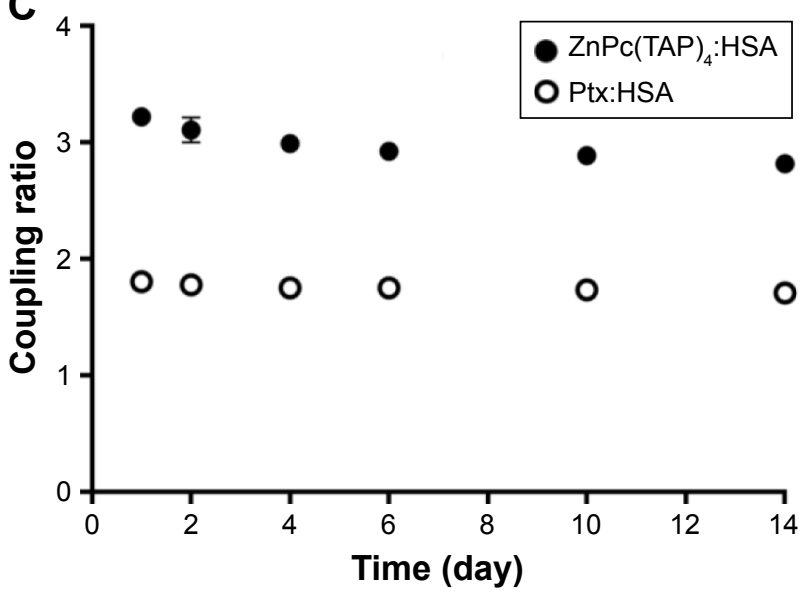

D

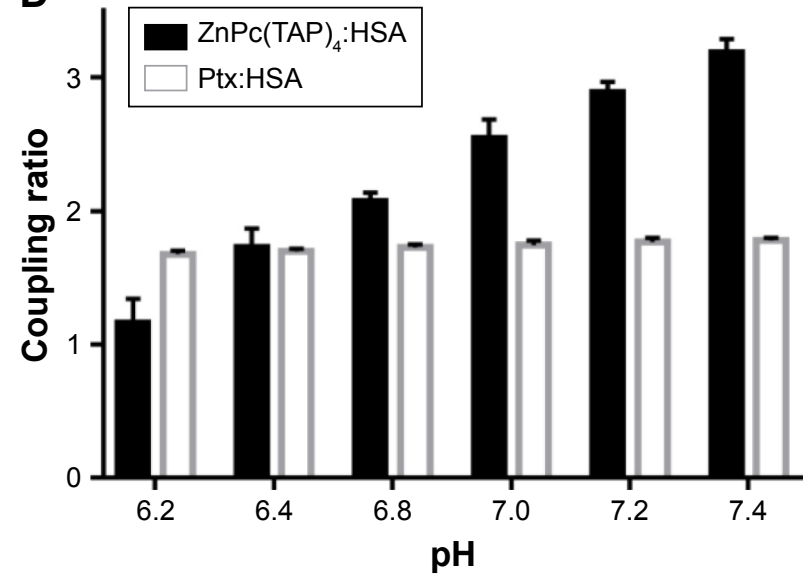

Figure 2 Characterization of $\mathrm{NP}-\mathrm{ZnPc}(\mathrm{TAP})_{4}-\mathrm{Ptx}$.

Notes: (A) Particle size of NP-ZnPc(TAP) ${ }_{4}-\mathrm{Ptx}$ detected using DLS: average $107 \mathrm{~nm}$. (B) The $\zeta$-potential was measured by DLS: average $-28 \mathrm{mV}$. The coupling ratio was defined by the ratio of $\mathrm{ZnPc}(\mathrm{TAP})_{4}$ concentration, Ptx concentration, and $\mathrm{HSA}$ concentration in the complex NP-ZnPc(TAP) ${ }_{4}-\mathrm{Ptx}$. (C) NP-ZnPc(TAP) $-\mathrm{Ptx}$ was stored in PBS with $\mathrm{pH} 7.4$ for 14 days. Coupling ratios of $\mathrm{ZnPc}(\mathrm{TAP})_{4}: \mathrm{HSA}$ and Ptx:HSA barely changed, which showed the stability of the complex. (D) The coupling ratio of Ptx:HSA was almost unchanged at any $\mathrm{pH}$. The reduced coupling ratio of $\mathrm{ZnPc}(\mathrm{TAP})_{4}: \mathrm{HSA}$ followed by $\mathrm{pH}$ decrease showed that $\mathrm{ZnPc}(\mathrm{TAP})_{4}$ molecules had escaped from $\mathrm{HSA} \mathrm{NPs}$. Abbreviations: ZnPc, zinc phthalocyanine; DLS, dynamic light scattering; Ptx, paclitaxel; HSA, human serum albumin.

(Figure 2A) and remained almost unchanged until 14 days, which demonstrated reasonable stability. The $\zeta$-potential of $\mathrm{NP}-\mathrm{ZnPc}(\mathrm{TAP})_{4}-\mathrm{Ptx}$ was $-28 \mathrm{mV}$ (Figure 2B), which indicated high colloidal stability.

\section{Drug release controlled by $\mathrm{pH}$}

An ideal NP-mediated drug-delivery system would not only transport drugs to diseased organs/cells but also release them in the target organ. Less leakage of drugs in NPs during transport and more release from NPs at the target location could enhance therapeutic effect and safety. Therefore, the drug-release behavior from the HSA NPs was detected. If $\mathrm{ZnPc}(\mathrm{TAP})_{4}$ was separated from HSA NPs, the coupling ratio of $\mathrm{HSA}$ and $\mathrm{ZnPc}(\mathrm{TAP})_{4}$ would change, so change in coupling ratio was used to monitor the release of $\mathrm{ZnPc}(\mathrm{TAP})_{4}$. The coupling ratio of $\mathrm{HSA}$ and $\mathrm{ZnPc}(\mathrm{TAP})_{4}$ was $1: 3$ in PBS 
with $\mathrm{pH}$ 7.4, which approached $\mathrm{pH}$ under physiological conditions. The coupling ratio barely changed during continuous monitoring for 14 days (Figure 2C), which showed favorable stability. Conversely, the coupling ratio was gradually transformed to $1: 2$ following $\mathrm{pH}$ dropping to 6.8 . When the $\mathrm{pH}$ was reduced to 6.2 , the coupling ratio became 1:1.2 (Figure 2D). These results suggested that $\mathrm{ZnPc}(\mathrm{TAP})_{4}$ was released from the HSA nanocarrier in an acidic environment. The coupling ratio of HSA and Ptx was unchanged during detection lasting for 14 days (Figure 2C), and Ptx release was not affected by pH in PBS (Figure 2D).

\section{Obvious cytotoxicity of $\mathrm{NP}-\mathrm{ZnPc}(\mathrm{TAP})_{4}-\mathrm{Ptx}$}

The cytotoxicity of drugs in vivo was the foundation of antitumor effects in vitro. H1299 cells were taken as research objects, and the cytotoxicity of $\mathrm{NP}-\mathrm{ZnPc}(\mathrm{TAP})_{4}-\mathrm{Ptx}$ was detected using $\mathrm{NP}-\mathrm{ZnPc}(\mathrm{TAP})_{4}$ and $\mathrm{ZnPc}(\mathrm{TAP})_{4}$ as contrast. After uptake for 24 hours, H1299 cells were illuminated by an LED light source $(680 \mathrm{~nm}, 100 \mathrm{~mW})$. Then, cell viability was measured through apoptosis for another 24 hours. Figure $3 \mathrm{~A}$ shows the phototoxicity of $\mathrm{NP}-\mathrm{ZnPc}(\mathrm{TAP})_{4}, \mathrm{ZnPc}(\mathrm{TAP})_{4}$, and $\mathrm{NP}-\mathrm{ZnPc}(\mathrm{TAP})_{4}-\mathrm{Ptx}$ for $\mathrm{H} 1299$ cells. Their dark toxicity was also measured with the same method, just without light, and the results are shown in Figure 3B. Both $\mathrm{ZnPc}(\mathrm{TAP})_{4}$ and $\mathrm{NP}-\mathrm{ZnPc}(\mathrm{TAP})_{4}$ had little dark toxicity, and the cellsurvival rate was $\sim 90 \%$ at $50 \mu \mathrm{M}$ concentration, which reflected the nontoxicity of HSA NPs as drug carriers. However, $\mathrm{ZnPc}(\mathrm{TAP})_{4}$ showed distinct phototoxicity and the cell-survival rate gradually decreased as the concentration of $\mathrm{ZnPc}(\mathrm{TAP})_{4}$ increased, which demonstrated the photodynamic activity of $\mathrm{ZnPc}(\mathrm{TAP})_{4}$. NP-ZnPc(TAP) showed enhanced phototoxicity compared with $\mathrm{ZnPc}(\mathrm{TAP})_{4}$, which may have been due to the loading capacity of HSA NPs for a mass of $\mathrm{ZnPc}(\mathrm{TAP})_{4}$. It was noteworthy that $\mathrm{NP}$ $\mathrm{ZnPc}(\mathrm{TAP})_{4}-\mathrm{Ptx}$ with an additional therapeutic agent, the chemotherapy drug Ptx, had stronger cytotoxicity, including phototoxicity and dark toxicity, than $\mathrm{NP}-\mathrm{ZnPc}(\mathrm{TAP})_{4}$ and $\mathrm{ZnPc}(\mathrm{TAP})_{4}$, with phototoxicity $\mathrm{IC}_{50} 4 \pm 0.23 \mu \mathrm{M}$. In addition, $\mathrm{NP}-\mathrm{ZnPc}(\mathrm{TAP})_{4}-\mathrm{Ptx}$ still had enhanced cytotoxicity over NP-Ptx under illumination conditions (Figure S2). It illustrated that the combined application of Ptx and $\mathrm{ZnPc}(\mathrm{TAP})_{4}$ created a synergistic effect.

\section{Time-dependent cellular localization of $\mathrm{NP}-\mathrm{ZnPc}(\mathrm{TAP})_{4}-\mathrm{Ptx}$}

ROS generated by PDT migrated only $<0.02 \mu \mathrm{m}$ after formation, ${ }^{11}$ so the cellular localization of the photosensitizer was most probably its active site. In addition, the difference in subcellular localization possibly led to the different cytotoxic mechanisms and effects. After H1299 cells had been incubated with $\mathrm{NP}-\mathrm{ZnPc}(\mathrm{TAP})_{4}-\mathrm{Ptx}$ for 30 minutes or 2 hours, mitochondria and lysosomes were marked by relevant probes. The subcellular localization of $\mathrm{NP}-\mathrm{ZnPc}(\mathrm{TAP})_{4}-\mathrm{Ptx}$ in
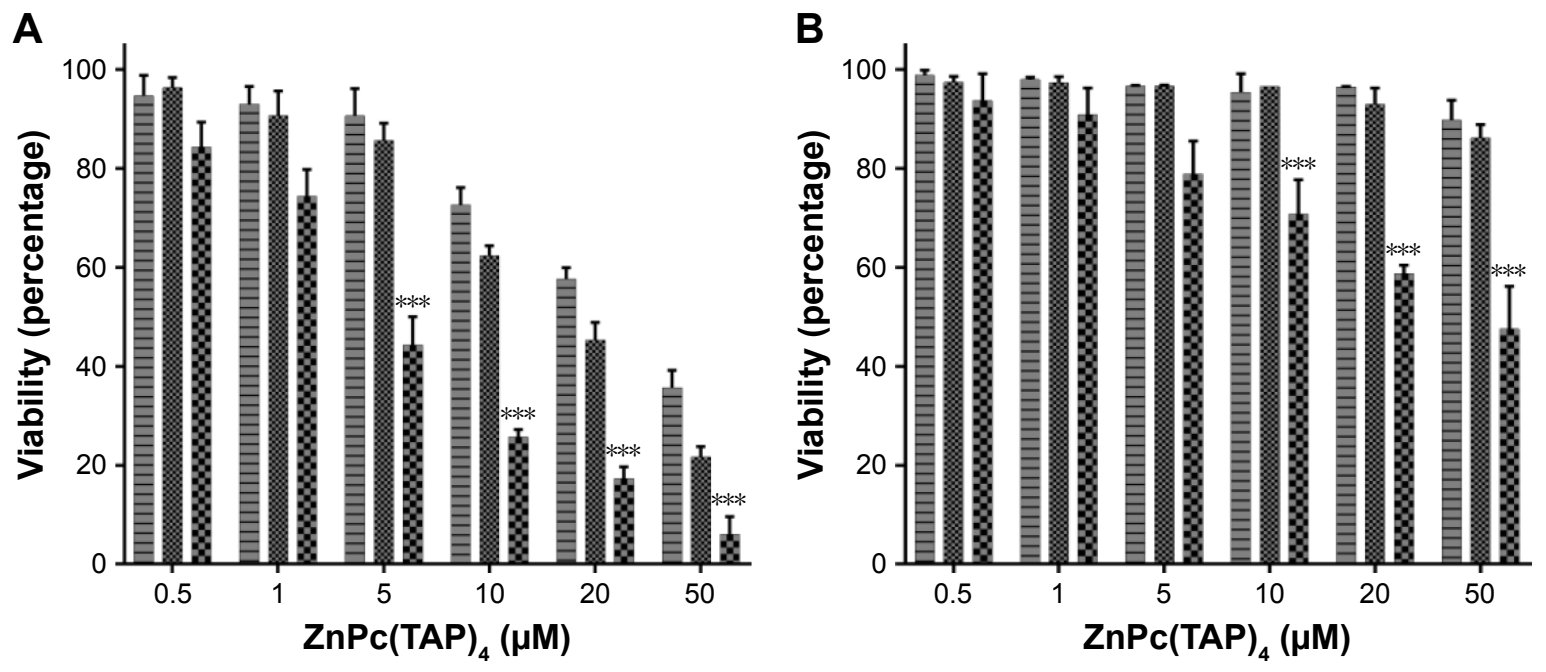

$$
\text { Q NP-ZnPc(TAP) })_{4}-\mathrm{Ptx} \quad \mathrm{Znnc}(\mathrm{TAP})_{4}
$$

Figure 3 Cytotoxicity of NP-ZnPc(TAP) $)_{4}-\mathrm{Ptx}, \mathrm{NP}-\mathrm{ZnPc}(\mathrm{TAP})_{4}$ and $\mathrm{ZnPc}(\mathrm{TAP})_{4}$ for $\mathrm{HI} 299$ cells.

Notes: A total of 8,000 adherent cells were cultivated in I-well of 96 -well plates and absorbed $\mathrm{NP}-\mathrm{ZnPc}(\mathrm{TAP})_{4}-\mathrm{Ptx}, \mathrm{NP}-\mathrm{ZnPc}(\mathrm{TAP})_{4}$, or $\mathrm{ZnPc}(\mathrm{TAP})_{4}$ at different concentrations $(0.5 \mu \mathrm{M}, \mathrm{I} \mu \mathrm{M}, 5 \mu \mathrm{M}, 10 \mu \mathrm{M}, 20 \mu \mathrm{M}$, or $50 \mu \mathrm{M})$ for 24 hours. Then, cells were illuminated with light fluence of I.5 J/cm ${ }^{2}$ for I minute. After 24 hours for apoptosis, viable cells were checked by MTT. (A) The phototoxicity of three samples depended on their concentrations, and NP-ZnPc(TAP) ${ }_{4}-\mathrm{Ptx}$ had the strongest phototoxicity for the synergistic effect of PDT and chemotherapy. (B) Dark toxicity was detected in the same way, just without illumination. NP-ZnPc(TAP) ${ }_{4}$ and $\mathrm{ZnPc}(\mathrm{TAP})_{4}$ had hardly any dark toxicity, and the dark toxicity of $\mathrm{NP}-\mathrm{ZnPc}(\mathrm{TAP})_{4}-\mathrm{Ptx}$ was significantly weaker than its phototoxicity. $* * * P<0.001$.

Abbreviations: NP, nanoparticle; ZnPc, zinc phthalocyanine; Ptx, paclitaxel; PDT, photodynamic therapy. 

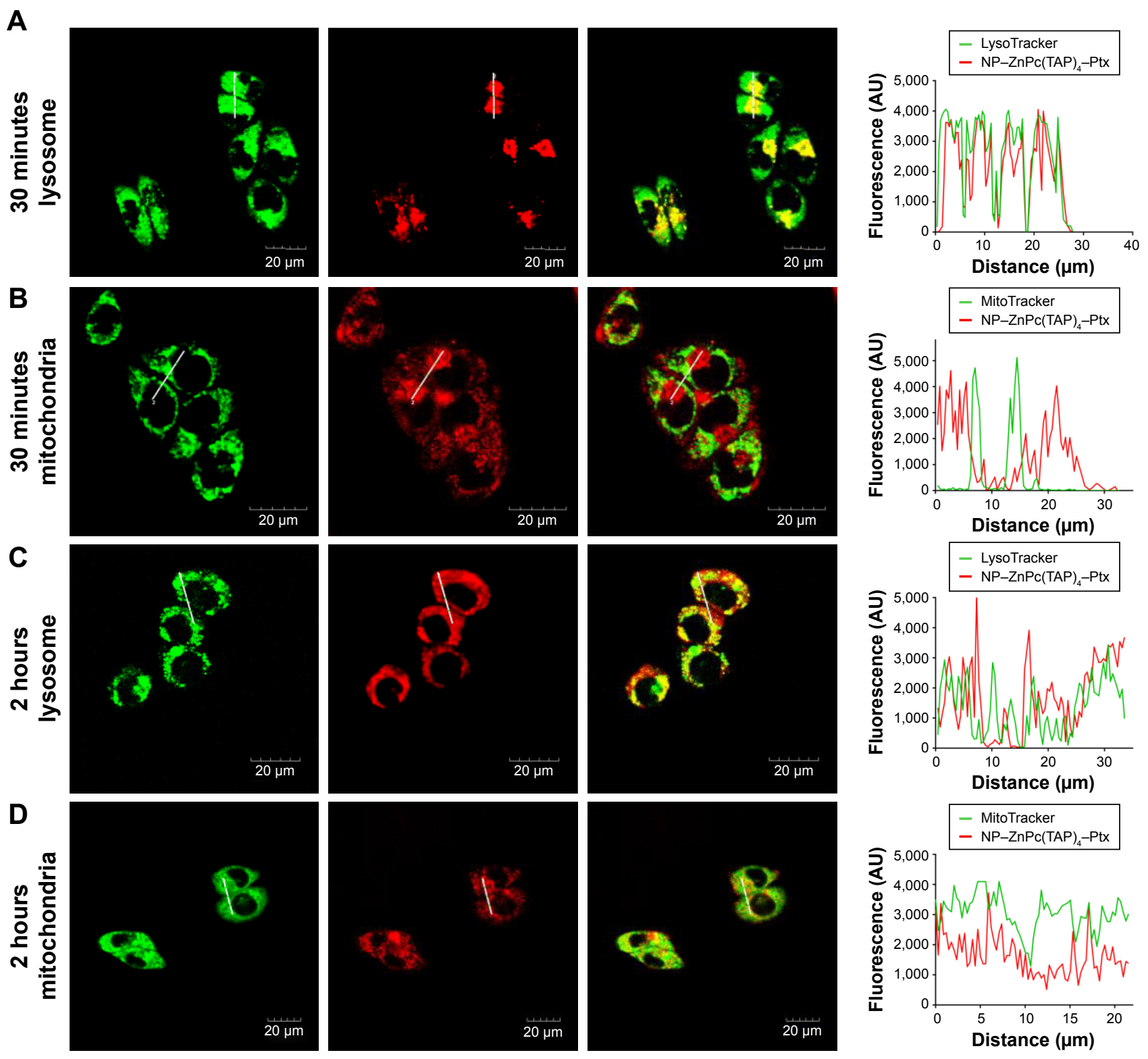

Figure 4 Time-dependent subcellular localization of NP-ZnPc(TAP) $-\mathrm{Ptx}$.

Notes: (A) The fluorescence of lysosomes (green) and NP-ZnPc(TAP) $-\mathrm{Ptx}$ (red) was merged to show yellow, and the fluorescence-intensity profiles of NP-ZnPc(TAP) ${ }_{4}^{-}$ Ptx and lysosomes further proved their colocation after incubation for 30 minutes. (B) There was little yellow through the merging of the fluorescence of mitochondria (green) and $\mathrm{NP}-\mathrm{ZnPc}(\mathrm{TAP})_{4}-\mathrm{Ptx}$ (red), and their fluorescence intensity had little overlap after incubation of 30 minutes. After 2 hours' incubation, the merged image and fluorescence-intensity profile showed that $\mathrm{NP}-\mathrm{ZnPc}(\mathrm{TAP})_{4}-\mathrm{Ptx}$ had not only distributed in lysosomes (C) but also in mitochondria (D).

Abbreviations: NP, nanoparticle; ZnPc, zinc phthalocyanine; Ptx, paclitaxel.

mitochondria and lysosomes was detected by laser-scanning confocal microscopy (Figure 4). Figure 4A shows the fluorescence of lysosomes and $\mathrm{NP}-\mathrm{ZnPc}(\mathrm{TAP})_{4}-\mathrm{Ptx}$, and the merger of the two after 30 minutes' incubation, which indicated almost complete coincidence. Fluorescence-intensity profiles of NP- $\mathrm{ZnPc}(\mathrm{TAP})_{4}-\mathrm{Ptx}$ and lysosomes (Figure 4A) further proved that $\mathrm{NP}-\mathrm{ZnPc}(\mathrm{TAP})_{4}-\mathrm{Ptx}$ was located mainly in lysosomes. Similarly, Figure 4B shows the fluorescence of mitochondria and $\mathrm{NP}-\mathrm{ZnPc}(\mathrm{TAP})_{4}-\mathrm{Ptx}$ and the merger of the two. Fluorescence-intensity profiles reflected that most $\mathrm{NP}-\mathrm{ZnPc}(\mathrm{TAP})_{4}-\mathrm{Ptx}$ had not located at mitochondria. While $\mathrm{H} 1299$ cells were incubated with $\mathrm{NP}-\mathrm{ZnPc}(\mathrm{TAP})_{4}-\mathrm{Ptx}$ for 2 hours, $\mathrm{NP}-\mathrm{ZnPc}(\mathrm{TAP})_{4}-\mathrm{Ptx}$ was not only distributed in lysosomes but also in mitochondria from the results of subcellular localization (Figure 4C and D).

\section{Enhanced tumor targeting of $\mathrm{NP}-\mathrm{ZnPc}(\mathrm{TAP})_{4}-\mathrm{Ptx}$}

As drug carriers, NPs deliver drugs to target organs to improve therapeutic effect. Did NP-ZnPc(TAP $)_{4}-\mathrm{Ptx}$ carry more drug 
to tumors in vivo? The H22 tumor-bearing mouse model was successfully built and used to evaluate the tumor targeting of $\mathrm{NP}-\mathrm{ZnPc}(\mathrm{TAP})_{4}-\mathrm{Ptx}$ with $\mathrm{ZnPc}(\mathrm{TAP})_{4}$ as contrast. After injection of $\mathrm{NP}-\mathrm{ZnPc}(\mathrm{TAP})_{4}-\mathrm{Ptx}$ and $\mathrm{ZnPc}(\mathrm{TAP})_{4}$, tumor-targeting capability in $\mathrm{H} 22$ tumor-bearing mice was monitored by FMT at 1, 2, 4, 12, 24, and 48 hours. Through $3 \mathrm{D}$ construction and quantitative analysis using TrueQuant (Figure 5), both NP-ZnPc(TAP) $)_{4}-\mathrm{Ptx}$ and $\mathrm{ZnPc}(\mathrm{TAP})_{4}$ had distributed rapidly to tumor sites (Figure 5A) at 1 hour. After 2 hours, the concentration of $\mathrm{ZnPc}(\mathrm{TAP})_{4}$ for the mice treated with $\mathrm{NP}-\mathrm{ZnPc}(\mathrm{TAP})_{4}-\mathrm{Ptx}$ was about 1.6 times that of mice treated with $\mathrm{ZnPc}(\mathrm{TAP})_{4}$ (Figure 5C). At 4 hours, there was the highest concentration of $\mathrm{ZnPc}(\mathrm{TAP})_{4}$ in tumors in $\mathrm{NP}-\mathrm{ZnPc}(\mathrm{TAP})_{4}$-Ptx and $\mathrm{ZnPc}(\mathrm{TAP})_{4}$ group, while NP-ZnPc(TAP) $)_{4}$-Ptx group had 1.8-fold the concentration of $\mathrm{ZnPc}(\mathrm{TAP})_{4}$ in tumors than the $\mathrm{ZnPc}(\mathrm{TAP})_{4}$ group. After 4 hours, the $\mathrm{ZnPc}(\mathrm{TAP})_{4}$ concentration in tumors of the $\mathrm{ZnPc}(\mathrm{TAP})_{4}$ group had decreased slightly and remained lower than the $\mathrm{NP}-\mathrm{ZnPc}(\mathrm{TAP})_{4}-\mathrm{Ptx}$ group up to 48 hours. Though the concentration of $\mathrm{ZnPc}(\mathrm{TAP})_{4}$ in tumors of the NP-ZnPc(TAP) $)_{4}-\mathrm{Ptx}$ group had reduced at 12 hours, it had another rise at 24 hours, which generated
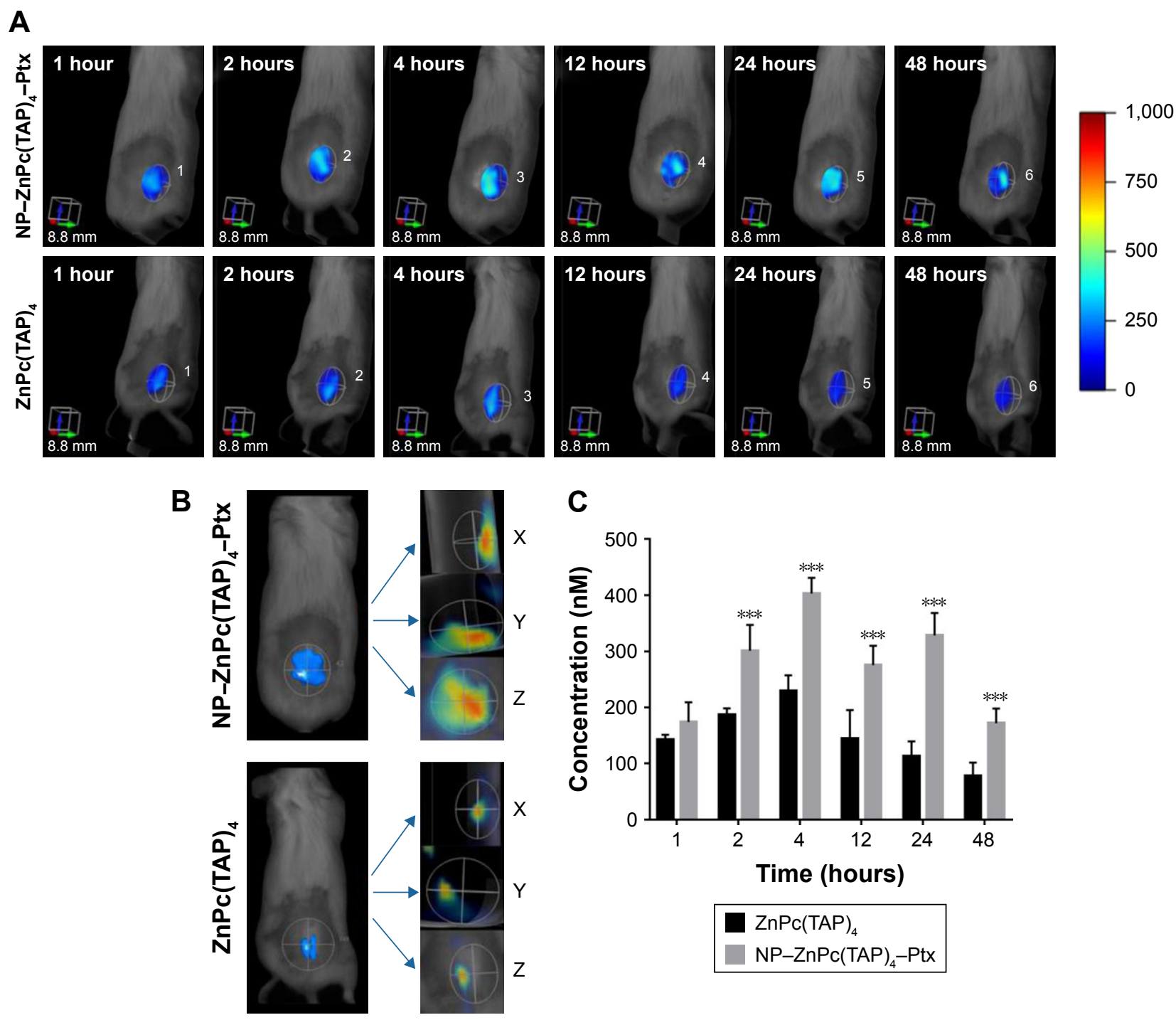

C

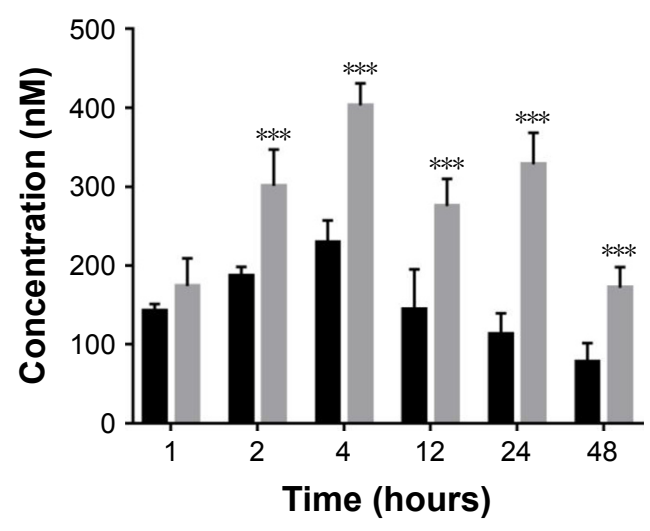

$\mathrm{ZnPc}(\mathrm{TAP})_{4}$

$\mathrm{NP}-\mathrm{ZnPc}(\mathrm{TAP})_{4}-\mathrm{Ptx}$

Figure 5 Tumor-targeting capabilities of $\mathrm{NP}-\mathrm{ZnPc}(\mathrm{TAP})_{4}-\mathrm{Ptx}$ evaluated by noninvasive 3D FMT $2500 \mathrm{LX}$ in $\mathrm{H} 22$ tumor-bearing Kunming mice.

Notes: (A) Three-dimensional images of accumulation of $\mathrm{NP}-\mathrm{ZnPc}(\mathrm{TAP})_{4}-\mathrm{Ptx}$ and $\mathrm{ZnPc}(\mathrm{TAP})_{4}$ at tumor sites after injection at I hour, 2 hours, 4 hours, 12 hours, 24 hours, and 48 hours showed that $\mathrm{NP}-\mathrm{ZnPc}(\mathrm{TAP})_{4}-\mathrm{Ptx}$ had higher tumor retention than $\mathrm{ZnPc}(\mathrm{TAP})_{4}$. (B) Isosurface rendering of 3D FMT reconstruction and three orthogonal slices ( $\mathrm{X}$ axial, $\mathrm{Y}$ axial, $\mathrm{Z}$ axial) across tumor centers at 24 hours after injection. The $\mathrm{ZnPc}(\mathrm{TAP})_{4}$ 3D shape constructed by the isosurface at tumor sites of $\mathrm{NP}-\mathrm{ZnPc}(\mathrm{TAP})_{4}-$ $\mathrm{Ptx}$ group was almost the same as the actual tumor shape. Slices showed that $\mathrm{ZnPc}(\mathrm{TAP})_{4}$ entered tumor centers in both groups, and the NP-ZnPc(TAP) ${ }_{4}-\mathrm{Ptx}$ group had more extensive distribution of $\mathrm{ZnPc}(\mathrm{TAP})_{4}$ within tumors. (C) Quantification of average $\mathrm{ZnPc}(\mathrm{TAP})_{4}$ concentrations in tumors for $\mathrm{NP}-\mathrm{ZnPc}(\mathrm{TAP})_{4}-\mathrm{Ptx}$ and $\mathrm{ZnPc}(\mathrm{TAP})_{4}$ groups at different times. The NP- $\mathrm{ZnPc}(\mathrm{TAP})_{4}-\mathrm{Ptx}$ group possessed higher concentrations of $\mathrm{ZnPc}(\mathrm{TAP})_{4}$ than $\mathrm{ZnPc}(\mathrm{TAP})_{4}$ group at any detection time point, and there was triple the difference at 24 hours. $* * * P<0.001$.

Abbreviations: NP, nanoparticle; ZnPc, zinc phthalocyanine; Ptx, paclitaxel; FMT, fluorescence molecular tomography. 
A

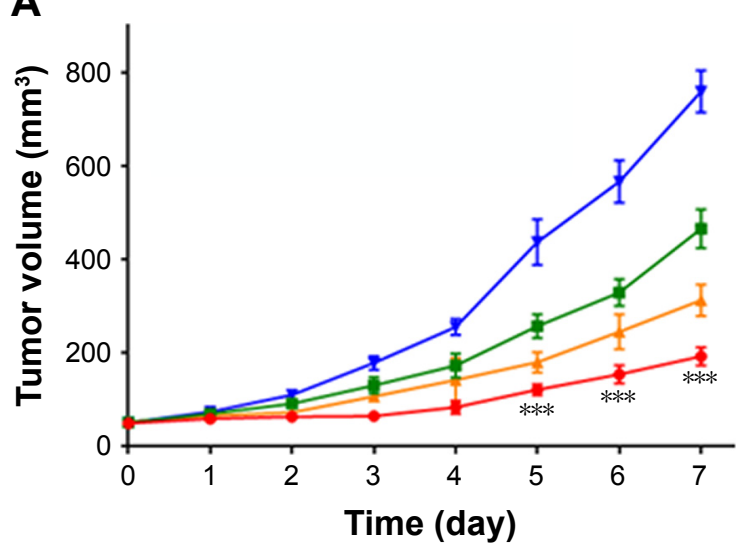

B

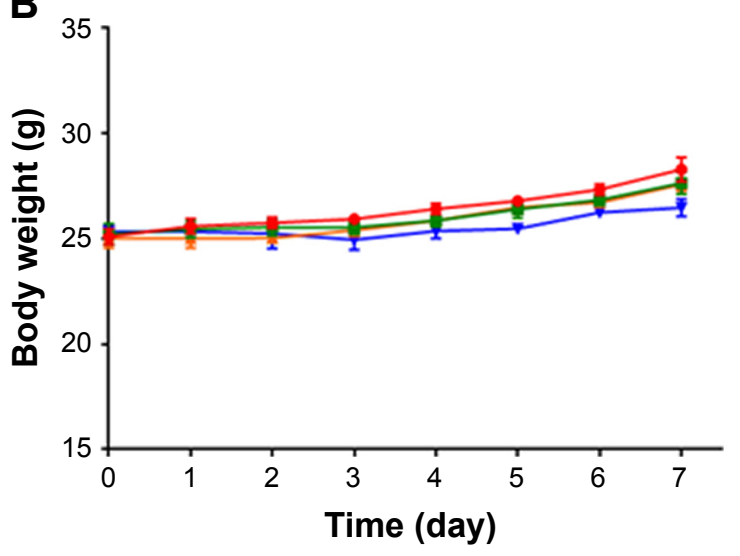

$\rightarrow \mathrm{NP}-\mathrm{ZnPc}(\mathrm{TAP})_{4}-\mathrm{Ptx} \rightarrow \mathrm{ZnPc}(\mathrm{TAP})_{4} \leadsto \mathrm{NP}-\mathrm{ZnPc}(\mathrm{TAP})_{4} \rightarrow$ Control

Figure 6 Therapy efficacy of NP-ZnPc(TAP) ${ }_{4}-\mathrm{Ptx}, \mathrm{ZnPc}(\mathrm{TAP})_{4}$, and $\mathrm{NP}-\mathrm{ZnPc}(\mathrm{TAP})_{4}$.

Notes: (A) Tumor-bearing Kunming mice were illuminated daily for 7 days and tumor sizes measured every day. NP-ZnPc(TAP) $-\mathrm{Ptx}$ had enhanced antitumor effects over $\mathrm{ZnPc}(\mathrm{TAP})_{4}$ and $\mathrm{NP}-\mathrm{ZnPc}(\mathrm{TAP})_{4}$ * $* * * \mathrm{P}<0.00 \mathrm{I}$. (B) Body weights of the mice were measured every day. During 7 days, the body weights were slightly elevated, with no significant differences among the four groups.

Abbreviations: NP, nanoparticle; ZnPc, zinc phthalocyanine; Ptx, paclitaxel.

a threefold difference between the two groups (Figure 5C). The results showed that $\mathrm{NP}-\mathrm{ZnPc}(\mathrm{TAP})_{4}-\mathrm{Ptx}$ had an enhanced tumor-targeting effect. In addition, the isosurface conformation was established by FMT at a concentration of $250 \mathrm{nM} \mathrm{ZnPc}(\mathrm{TAP})_{4}$ (Figure 5B) at tumor sites at 24 hours. The isosurface of $\mathrm{ZnPc}(\mathrm{TAP})_{4}$ with mice treated with $\mathrm{NP}-\mathrm{ZnPc}(\mathrm{TAP})_{4}-\mathrm{Ptx}$ was obviously larger than mice treated by $\mathrm{ZnPc}(\mathrm{TAP})_{4}$. What is more, the volume and the boundary of isosurface rendering with the mice treated by $\mathrm{NP}-\mathrm{ZnPc}(\mathrm{TAP})_{4}-\mathrm{Ptx}$ were very close to that of actual tumors. The absence of tumor boundaries was a serious handicap for surgery. As a probe, NP-ZnPc(TAP) - Ptx might provide support to determine tumor boundaries. Three orthogonal slices ( $\mathrm{X}$ axial, $\mathrm{Y}$ axial, $\mathrm{Z}$ axial) across the tumor center showed the distribution of $\mathrm{ZnPc}(\mathrm{TAP})_{4}$ within tumors (Figure 5B). It was found that $\mathrm{ZnPc}(\mathrm{TAP})_{4}$ of both $\mathrm{NP}-\mathrm{ZnPc}(\mathrm{TAP})_{4}-\mathrm{Ptx}$ and $\mathrm{ZnPc}(\mathrm{TAP})_{4}$ groups entered tumor centers and $\mathrm{ZnPc}(\mathrm{TAP})_{4}$ of the NP-ZnPc(TAP) ${ }_{4}-\mathrm{Ptx}$ group had more extensive distribution, which further proved the targeting ability of $\mathrm{NP}-\mathrm{ZnPc}(\mathrm{TAP})_{4}-\mathrm{Ptx}$.

\section{Enhanced antitumor effect of $\mathrm{NP}-\mathrm{ZnPc}(\mathrm{TAP})_{4}-\mathrm{Ptx}$}

The established $\mathrm{H} 22$ tumor-bearing mice were injected with $\mathrm{NP}-\mathrm{ZnPc}(\mathrm{TAP})_{4}-\mathrm{Ptx}, \mathrm{NP}-\mathrm{ZnPc}(\mathrm{TAP})_{4}$, and $\mathrm{ZnPc}(\mathrm{TAP})_{4}$ using normal saline as contrast. During the daily illumination therapy for 7 days, tumor size was measured every day, and the tumor-growth curve was showed in Figure 6A. Compared with the control, $\mathrm{NP}-\mathrm{ZnPc}(\mathrm{TAP})_{4}-\mathrm{Ptx}, \mathrm{NP}-\mathrm{ZnPc}(\mathrm{TAP})_{4}$ and
$\mathrm{ZnPc}(\mathrm{TAP})_{4}$, all inhibited tumor growth. In particular, tumor sizes in mice treated with $\mathrm{NP}-\mathrm{ZnPc}(\mathrm{TAP})_{4}-\mathrm{Ptx}$ reduced about four times those of the control. $\mathrm{ZnPc}(\mathrm{TAP})_{4}$ had weaker antitumor effects than $\mathrm{NP}-\mathrm{ZnPc}(\mathrm{TAP})_{4}-\mathrm{Ptx}$ and $\mathrm{NP}-\mathrm{ZnPc}(\mathrm{TAP})_{4}$, which may have been due to its weaker tumor-targeting effect (see experimental results in the section of "Enhanced tumor targeting of $\mathrm{NP}-\mathrm{ZnPc}(\mathrm{TAP})_{4}-\mathrm{Ptx}$ "). NP-ZnPc(TAP) $)_{4}-\mathrm{Ptx}$ had stronger antitumor effect than $\mathrm{NP}-\mathrm{ZnPc}(\mathrm{TAP})_{4}$, which illustrated the synergistic anticancer effect of PDT and chemotherapy, in accord with the results of cytotoxicity. During the whole course of treatment, no distinct difference in body weight was observed among the three groups (Figure 6B).

\section{Discussion}

\section{Nonaggregated $\mathrm{ZnPc}(\mathrm{TAP})_{4}$ generated by electrostatic repulsive force}

$\mathrm{ZnPc}$ with a 2D 18-electron system exhibited a high aggregation tendency of dimeric and oligomeric formation. The aggregation was classified as face to face (H-type aggregate), slipped cofacial (H-aggregate for $0^{\circ}<\theta<54.7^{\circ}$ or J-aggregate for $54.7^{\circ}<\theta<90^{\circ}$ ), and pure head to tail (J-type aggregate). Some peripheral substituents containing oxygen or nitrogen atoms coordinated with $\mathrm{Zn}^{2+}$ in another adjacent molecule, which controlled intermolecular H-type aggregation. ${ }^{14}$ Some solvents, such as dimethylformamide, dimethylsulfoxide, and pyridine, have the same effect when coordinated with $\mathrm{Zn}^{2+}$. The steric-hindrance effect of peripheral substituents can also influence the aggregation behavior of $\mathrm{ZnPc}$. In addition, charged substituents containing cations or anions hinder aggregation 
through electrostatic repulsive force. On account of the protonation effect of tertiary amine groups in substituents, peripheral substituents carry positive charges in the acidic environment. Therefore, $\mathrm{ZnPc}(\mathrm{TAP})_{4}$ was speculated to exist in monomer form with an absorption peak at $680 \mathrm{~nm}$ with $\mathrm{pH} 6.0$ and 6.2. As the $\mathrm{pH}$ rose to 7.6, the monomer peak gradually lowered, which suggested aggregation was generated. Meanwhile, an unusual red-shifted absorption peak at $700 \mathrm{~nm}$ occurred, which implied J-type aggregation of $\mathrm{ZnPc}(\mathrm{TAP})_{4}$. The emergence of J-type aggregation may be caused by subdued protonation of $\mathrm{ZnPc}(\mathrm{TAP})_{4}$ and reduced electrostatic repulsion interactions among molecules as $\mathrm{pH}$ rises. To some extent, the incomplete protonation of $\mathrm{ZnPc}(\mathrm{TAP})_{4}$ and the heterogeneous electrostatic repulsion interaction could result in head-to-tail aggregation. When the $\mathrm{pH}$ rose to 8.0 , the main absorption peak was blueshifted to $650 \mathrm{~nm}$, which may have been due to deprotonation and loss of electrostatic forces to generate most H-type aggregates in an alkaline environment.

\section{Loading $\mathrm{ZnPc}(\mathrm{TAP})_{4}$ and Ptx into HSA NPs}

By cleaving disulfide bonds of HSA, the structure of HSA became loose, which resulted in more hydrophobic domains of HSA being exposed. These increased hydrophobic domains were able to bind more hydrophobic drugs. $\mathrm{ZnPc}(\mathrm{TAP})_{4}(6.2 \mathrm{mg})$ was dissolved in $0.5 \mathrm{~mL}$ ethanol (7.6 mM), and Ptx (1.3 mg) was also dissolved in $100 \mu \mathrm{L}$ DMSO completely (15.2 mM). After they were added to HSA solution with high concentration, $\mathrm{ZnPc}(\mathrm{TAP})_{4}$ and $\mathrm{Ptx}$ bound to HSA by hydrophobic interaction. The HSA NPs loading $\mathrm{ZnPc}(\mathrm{TAP})_{4}$ and $\mathrm{Ptx}, \mathrm{NP}-\mathrm{ZnPc}(\mathrm{TAP})_{4}-\mathrm{Ptx}$ were dialyzed to PBS ( $\mathrm{pH} 7.4$ ) three times to remove ethanol and DMSO that was not bound to HSA.

Many interactions may contribute to the binding of $\mathrm{ZnPc}(\mathrm{TAP})_{4}$ and Ptx to HSA. The tertiary amine substituents of $\mathrm{ZnPc}(\mathrm{TAP})_{4}$ could form hydrogen bonds with HSA, and $\pi-\pi$ interactions may exist between $\mathrm{ZnPc}(\mathrm{TAP})_{4}$ and aminoacid residues. Hydrophobic interaction was supposed to be the main interaction force. Ptx is a chemotherapy drug with strong hydrophobicity, and had strong affinity with HSA by hydrophobic interaction. In alkaline solution, the hydrophobicity of $\mathrm{ZnPc}(\mathrm{TAP})_{4}$ was increased by deionization, leading to binding to HSA by hydrophobic force. The release of $\mathrm{ZnPc}(\mathrm{TAP})_{4}$ with $\mathrm{pH}$ decreased further illustrated the importance of hydrophobic interactions in this loading. It was most probable that not all $\mathrm{ZnPc}(\mathrm{TAP})_{4}$ and Ptx were loaded into HSA NPs. Free $\mathrm{ZnPc}(\mathrm{TAP})_{4}$ was water-soluble and was removed from $\mathrm{NP}-\mathrm{ZnPc}(\mathrm{TAP})_{4}-\mathrm{Ptx}$ by centrifugation.
The precipitate caused by unloaded Ptx in PBS was intercepted at the top of the DEAE column. In addition, free HSA adhered to the DEAE column, while NP-ZnPc(TAP) $-\mathrm{Ptx}$ flowed through the column. By these purification methods, it was ensured that both $\mathrm{ZnPc}(\mathrm{TAP})_{4}$ and $\mathrm{Ptx}$ were loaded into NPs in the final NP-ZnPc(TAP) $)_{4}-\mathrm{Ptx}$ solution.

\section{Controlled release of $\mathrm{ZnPc}(\mathrm{TAP})_{4}$ from HSA NPs at tumor sites}

In solid-tumor tissue, high glycolytic activity was the common characteristic leading to increased production and secretion of lactate and $\mathrm{H}^{+}$to the extracellular space. Although tumor $\mathrm{pH}$ may vary according to tumor area, the average extracellular tumor $\mathrm{pH}$ was between 6.0 and 7.0 and below the $\mathrm{pH}$ in normal tissue and blood (around 7.4). ${ }^{15}$ The very sensitive response to $\mathrm{NP}-\mathrm{ZnPc}(\mathrm{TAP})_{4}-\mathrm{Ptx} \mathrm{pH}$ made $\mathrm{ZnPc}(\mathrm{TAP})_{4}$ release at the tumor site, and released $\mathrm{ZnPc}(\mathrm{TAP})_{4}$ more adequately engaged in mutual contact and interaction with tumor cells or cellular substrates, which may improve the PDT effect.

Why could $\mathrm{ZnPc}(\mathrm{TAP})_{4}$ be released in an acidic environment? This was probably related to some properties of $\mathrm{ZnPc}(\mathrm{TAP})_{4}$ itself. HSA molecules have some hydrophobic domains that can bind some hydrophobic drugs. $\mathrm{ZnPc}(\mathrm{TAP})_{4}$ was able to be loaded into HSA NPs due also to the hydrophobic interaction between $\mathrm{ZnPc}(\mathrm{TAP})_{4}$ and $\mathrm{HSA}$ molecules. However, in an acidic environment, the hydrophilicity of $\mathrm{ZnPc}(\mathrm{TAP})_{4}$ was increased by the protonation effect of peripheral substituents, which was demonstrated by the ultraviolet-visible spectra at acidic $\mathrm{pH}$. As such, the weakened hydrophobic interaction between $\mathrm{ZnPc}(\mathrm{TAP})_{4}$ and HSA molecules resulted in the separation of $\mathrm{ZnPc}(\mathrm{TAP})_{4}$ from HSA NPs.

\section{Synergistic anticancer effect with PDT and chemotherapy}

The therapeutic effect of PDT was seriously affected by the aggregation behavior of phthalocyanines. Especially in an aqueous solution, $\mathrm{ZnPc}$ had a strong aggregation trend for intermolecular interaction, leading to fluorescence quenching and lower ROS generation due to enhanced state dissipation without radiation and reduced lifetime of the excited state, while the aggregation of $\mathrm{ZnPc}(\mathrm{TAP})_{4}$ was limited by its tertiary amine substituents in an acidic environment at the tumor site. The higher singlet-oxygen quantum yields $\left(\Phi_{\Delta}\right)$ at lower $\mathrm{pH}$ (Table S1) was thought to be one of the reasons for the excellent PDT effect. Light penetration (about 1-2 mm) could also have affected the PDT effect. Compared with 
deep tumors in the body, subcutaneous tumors were easier to expose to light and be treated by PDT.

It is generally recognized that there are three mechanisms for killing tumor during the course of PDT. Universally, photosensitizers play an antitumor role through direct cellular damage under illumination, on account of which induced ROS can react directly with many biological molecules as an oxidizing agent. In addition, photosensitizers cause vascular leakage and microvascular collapse following PDT, leading to severe and persistent post-PDT tumor hypoxia that contributed to long-term tumor control. Finally, it is thought that PDT can induce a massive regulated invasion of inflammatory cells and generate a long-term antitumor immunoresponse. ${ }^{16}$ However, Ptx is a microtubule-stabilizer and induces cytotoxicity by cutting off the cell cycle in the $\mathrm{G}_{2} / \mathrm{M}$ phase. ${ }^{17}$ Therefore, it could be seen that $\mathrm{ZnPc}(\mathrm{TAP})_{4}$ and Ptx had different antitumor-action mechanisms. The independent dual role of phototherapy and chemotherapy brought out enhanced cytotoxicity.

\section{Preferential distribution in lysosomes and then diffusion into mitochondria}

Endocytosis is a mechanism common to all cells in the body for internalizing macromolecules. It has been reported that the primary cell-internalization pathway of NPs was endocytosis, with subsequent distribution to endosomes and then lysosomes. ${ }^{18}$ The result of subcellular localization showed that $\mathrm{NP}-\mathrm{ZnPc}(\mathrm{TAP})_{4}-\mathrm{Ptx}$ almost completely distributed in lysosomes. Therefore, $\mathrm{NP}-\mathrm{ZnPc}(\mathrm{TAP})_{4}-\mathrm{Ptx}$ were more likely to be internalized through endocytosis. Lysosomes and endosomes have an acidic environment ( $\mathrm{pH} 4.5-6.5){ }^{19}$ On account of protonation, the low $\mathrm{pH}$ in lysosomes result in the release of $\mathrm{ZnPc}(\mathrm{TAP})_{4}$ from $\mathrm{NP}-\mathrm{ZnPc}(\mathrm{TAP})_{4}-\mathrm{Ptx}$. The dissociative molecules of $\mathrm{ZnPc}(\mathrm{TAP})_{4}$ escaped lysosome limits and were distributed in other organelles, including mitochondria. This perhaps was the reason for the timedependent cellular localization of $\mathrm{NP}-\mathrm{ZnPc}(\mathrm{TAP})_{4}-\mathrm{Ptx}$.

\section{HSA NPs as tumor-targeting drug carriers}

Compared with healthy vessels in normal organs, tumors possess leaky blood vessels and impaired lymphatic drainage, which allows the selective access of NPs to tumors: the so-called enhanced permeability and retention effect. ${ }^{5}$ Therefore, the nanosize agent $\mathrm{NP}-\mathrm{ZnPc}(\mathrm{TAP})_{4}-\mathrm{Ptx}$ gathered in tumor tissue more than the small-molecule drug $\mathrm{ZnPc}(\mathrm{TAP})_{4}$. In addition, albumin binding to Gp60 on endothelial cells stimulated the activation of caveolin 1, which promoted transport of intact NPs across the cell membrane. The importance of Gp60 in albumin-drug transcytosis has been demonstrated. ${ }^{20}$ In tumor tissue, another protein, SPARC, which modulates the interaction of cells with the extracellular matrix, can bind and carry albumin to tumor cells. SPARC is overexpressed in multiple tumor types and is associated with increased tumor invasion and metastasis and poor prognosis. ${ }^{21}$ SPARC binding to albumin may be an another important fator in the increased tumor accumulation of albumin-bound drugs. These functions of albumin also facilitated the tumortargeting effect of $\mathrm{NP}-\mathrm{ZnPc}(\mathrm{TAP})_{4}-\mathrm{Ptx}$.

\section{A possible effect to overcome multidrug resistance (MDR)}

MDR accounts for $\sim 90 \%$ of chemotherapeutic drug failures in cancer patients. ${ }^{22}$ MDR seriously affects the therapeutic effect of Ptx, due to low tumor specificity, inadequate drug penetration to the tumor site, and rapid clearance from circulation, which lead to more intensive treatment regimens and debilitating side effects. ${ }^{23}$ MDR is mediated by different mechanisms, in particular overexpression of the drug-efflux transporter Pgp, which can transport chemotherapeutic drugs out of tumor cells. It has been reported that Ptx was a substrate of Pgp, which actively pumped Ptx out of cells and induced drug resistance. ${ }^{24}$ To overcome Pgp-mediated MDR, various Pgp inhibitors had been developed and coadministered with anticancer agents. However, inhibitors combined with antitumor drugs often result in enhanced drug side effects, due to the aspecific inhibition of Pgp leading to alteration of drug-elimination pathways in liver or kidney. ${ }^{25}$ Encapsulated Ptx has different mechanisms of entry into cells compared with free Ptx, and nanosize drug-delivery systems can reduce the cell Pgp-pump effect on drugs delivered intracellularly. ${ }^{26}$ Therefore, $\mathrm{NP}-\mathrm{ZnPc}(\mathrm{TAP})_{4}-\mathrm{Ptx}$ may be able to overcome MDR to some extent.

\section{Conclusion}

In our study, the photosensitizer $\mathrm{ZnPc}(\mathrm{TAP})_{4}$ was first found to have $\mathrm{pH}$-sensitive properties. We prepared HSA $\mathrm{NP}-\mathrm{ZnPc}(\mathrm{TAP})_{4}-\mathrm{Ptx}$ by a sulfhydryl self-assembly method loading the photosensitizer $\mathrm{ZnPc}(\mathrm{TAP})_{4}$ and the chemotherapy drug Ptx. NP-ZnPc(TAP) $)_{4}-\mathrm{Ptx}$ had good stability in physiological conditions, and $\mathrm{ZnPc}(\mathrm{TAP})_{4}$ was released from $\mathrm{NP}-\mathrm{ZnPc}(\mathrm{TAP})_{4}-\mathrm{Ptx}$ in acidic conditions. $\mathrm{NP}-\mathrm{ZnPc}(\mathrm{TAP})_{4}{ }_{-}$ Ptx enhanced cytotoxicity more than NP-ZnPc(TAP) ${ }_{4}$ and $\mathrm{ZnPc}(\mathrm{TAP})_{4}$ and had time-dependent properties for cellular localization. Animal experiments showed that $\mathrm{NP}-\mathrm{ZnPc}(\mathrm{TAP})_{4}-\mathrm{Ptx}$ had prominent tumor-targeting and 
synergistic antitumor effects. This $\mathrm{pH}$-sensitive drug-delivery system loading $\mathrm{ZnPc}(\mathrm{TAP})_{4}$ may be applied for simultaneous delivery of other chemotherapy drugs for synergistic anticancer purposes.

\section{Acknowledgment}

This work was supported by grants from the Qingdao Applied

Postdoctoral Research Project.

\section{Author contributions}

All authors contributed to data analysis, drafting and revising the article, gave final approval of the version to be published, and agree to be accountable for all aspects of the work.

\section{Disclosure}

The authors report no conflicts of interest in this work.

\section{References}

1. Lucky SS, Soo KC, Zhang Y. Nanoparticles in photodynamic therapy. Chem Rev. 2015;115(4):1990-2042.

2. Lukyanets EA. Phthalocyanines as photosensitizers in the photodynamic therapy of cancer. J Porphyr Phthalocyanines. 1999;3(6) 424-432.

3. Chatterjee DK, Fong LS, Zhang Y. Nanoparticles in photodynamic therapy: an emerging paradigm. Adv Drug Deliv Rev. 2008;60(15):1627-1637.

4. Moret F, Reddi E. Strategies for optimizing the delivery to tumors of macrocyclic photosensitizers used in photodynamic therapy (PDT). $J$ Porphyr Phthalocyanines. 2017;21(04-06):239-256.

5. Maeda H, Wu J, Sawa T, Matsumura Y, Hori K. Tumor vascular permeability and the EPR effect in macromolecular therapeutics: a review. $J$ Control Release. 2000;65(1-2):271-284.

6. Torchilin VP. Multifunctional, stimuli-sensitive nanoparticulate systems for drug delivery. Nat Rev Drug Discov. 2014;13(11):813-827.

7. Elzoghby AO, Samy WM, Elgindy NA. Albumin-based nanoparticles as potential controlled release drug delivery systems. J Control Release. 2012;157(2):168-182.

8. Weiszhár Z, Czúcz J, Révész C, Rosivall L, Szebeni J, Rozsnyay Z. Complement activation by polyethoxylated pharmaceutical surfactants: Cremophor-EL, Tween-80 and Tween-20. Eur J Pharm Sci. 2012;45(4): 492-498.

9. Makhseed S, Machacek M, Alfadly W, et al. Water-soluble nonaggregating zinc phthalocyanine and in vitro studies for photodynamic therapy. Chem Commun. 2013;49(95):11149-11151.

10. Li XS, Ke MR, Zhang MF, Tang QQ, Zheng BY, Huang JD. A nonaggregated and tumour-associated macrophage-targeted photosensitiser for photodynamic therapy: a novel zinc(II) phthalocyanine containing octa-sulphonates. Chem Commun. 2015;51(22):4704-4707.
11. Ağırtaş MS, Çelebi M, Gümüş S, Özdemir S, Okumuş V. New water soluble phenoxy phenyl diazenyl benzoic acid substituted phthalocyanine derivatives: synthesis, antioxidant activities, atypical aggregation behavior and electronic properties. Dyes Pigm. 2013;99(2): 423-431.

12. Synthesis BZ. Characterization and aggregation properties of watersoluble metal-free and metallophthalocyanines peripherally tetrasubstituted with 2-[2-(dimethylamino) ethoxy] ethoxy moiety. Synth Met. 2012;162(1-2):26-34.

13. Zhang Y, Zheng K, Chen Z, et al. Rapid killing of bacteria by a new type of photosensitizer. Appl Microbiol Biotechnol. 2017;101(11): $4691-4700$

14. Zhang X-F, Xi Q, Zhao J. Fluorescent and triplet state photoactive J-type phthalocyanine nano assemblies: controlled formation and photosensitizing properties. J Mater Chem. 2010;20(32):6726-6733.

15. Danhier F, Feron O, Préat V. To exploit the tumor microenvironment: passive and active tumor targeting of nanocarriers for anti-cancer drug delivery. J Control Release. 2010;148(2):135-146.

16. Castano AP, Demidova TN, Hamblin MR. Mechanisms in photodynamic therapy: part three-photosensitizer pharmacokinetics, biodistribution, tumor localization and modes of tumor destruction. Photodiagnosis Photodyn Ther. 2005;2(2):91-106.

17. Yu Y, Gaillard S, Phillip JM, et al. Inhibition of spleen tyrosine kinase potentiates paclitaxel-induced cytotoxicity in ovarian cancer cells by stabilizing microtubules. Cancer Cell. 2015;28(1):82-96.

18. Iversen T-G, Skotland T, Sandvig K. Endocytosis and intracellular transport of nanoparticles: present knowledge and need for future studies. Nano Today. 2011;6(2):176-185.

19. Altintas I, Heukers R, van der Meel R, et al. Nanobody-albumin nanoparticles (NANAPs) for the delivery of a multikinase inhibitor 17864 to EGFR overexpressing tumor cells. J Control Release. 2013;165(2): $110-118$.

20. Gradishar WJ. Albumin-bound paclitaxel: a next-generation taxane Expert Opin Pharmacother. 2006;7(8):1041-1053.

21. Kratz F. Albumin as a drug carrier: design of prodrugs, drug conjugates and nanoparticles. J Control Release. 2008;132(3):171-183.

22. Ullah MF. Cancer multidrug resistance (MDR): a major impediment to effective chemotherapy. Asian Pac J Cancer Prev. 2008;9(1):1-6.

23. Ma P, Mumper RJ. Paclitaxel nano-delivery systems: a comprehensive review. J Nanomed Nanotechnol. 2013;4(2):1000164.

24. Shieh MJ, Hsu CY, Huang LY, Chen HY, Huang FH, Lai PS. Reversal of doxorubicin-resistance by multifunctional nanoparticles in MCF-7/ ADR cells. J Control Release. 2011;152(3):418-425.

25. Koziara JM, Whisman TR, Tseng MT, Mumper RJ. In-vivo efficacy of novel paclitaxel nanoparticles in paclitaxel-resistant human colorectal tumors. J Control Release. 2006;112(3):312-319.

26. Sudha T, Bharali DJ, Yalcin M, et al. Targeted delivery of paclitaxel and doxorubicin to cancer xenografts via the nanoparticle of nanodiamino-tetrac. Int J Nanomedicine. 2017;12:1305-1315. 


\section{Supplementary materials}

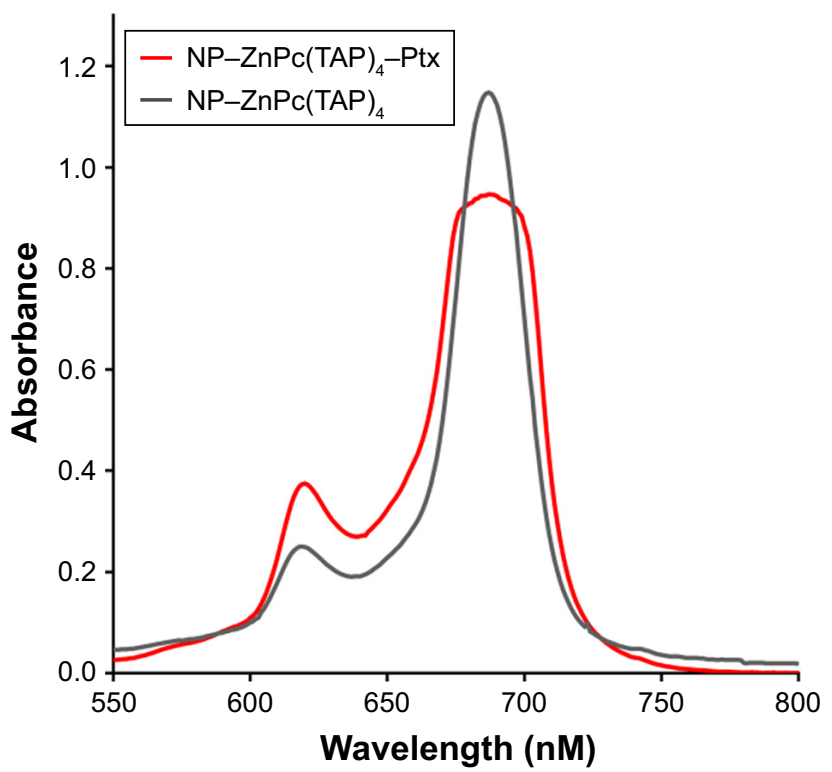

Figure SI Ultraviolet-visible spectra of NP-ZnPc(TAP) ${ }_{4}-\mathrm{Ptx}$ and NP-ZnPc(TAP) ${ }_{4}$ (the concentration of ZnPc[TAP] $]_{4}$ was $5 \mu M$ ) in PBS.

Notes: This result showed that $\mathrm{NP}-\mathrm{ZnPc}(\mathrm{TAP})_{4}-\mathrm{Ptx}$ and $\mathrm{NP}-\mathrm{ZnPc}(\mathrm{TAP})_{4}$, had almost the same spectrum, while the spectrum was different from that of $\mathrm{ZnPc}(\mathrm{TAP})_{4}$ in $\mathrm{PBS}$ without HSA (Figure IB). This suggested that $\mathrm{ZnPc}(\mathrm{TAP})_{4}$ interacted with $\mathrm{HSA}$ in the NPs.

Abbreviations: NP, nanoparticle; ZnPc, zinc phthalocyanine; Ptx, paclitaxel; HSA, human serum albumin.

Table SI Ultraviolet-visible and singlet-oxygen generation data for $\mathrm{ZnPc}(\mathrm{TAP})_{4}$ and $\mathrm{NP}-\mathrm{ZnPc}(\mathrm{TAP})_{4}-\mathrm{Ptx}$

\begin{tabular}{|c|c|c|c|c|c|c|c|c|c|c|}
\hline & pH & 6.0 & 6.2 & 6.4 & 6.8 & 7.0 & 7.2 & 7.4 & 7.6 & 8.0 \\
\hline $\mathrm{ZnPc}(\mathrm{TAP})_{4}$ & $\begin{array}{l}\Phi_{\Delta}^{a} \\
\lambda_{\max } / \mathrm{nm}\left(\log _{\varepsilon}\right)\end{array}$ & $\begin{array}{l}0.55 \\
680(5.5 \mathrm{I})\end{array}$ & $\begin{array}{l}0.52 \\
680(5.46)\end{array}$ & $\begin{array}{l}0.51 \\
680(5.45)\end{array}$ & $\begin{array}{l}0.48 \\
680(5.37) \\
700(5.27)\end{array}$ & $\begin{array}{l}0.45 \\
680(5.32) \\
700(5.34)\end{array}$ & $\begin{array}{l}0.43 \\
653(5.06) \\
680(5.21) \\
700(5.21)\end{array}$ & $\begin{array}{l}0.43 \\
653(4.95) \\
680(5.15) \\
700(5.12)\end{array}$ & $\begin{array}{l}0.41 \\
653(5.13) \\
680(5.09) \\
700(5.06)\end{array}$ & $\begin{array}{l}0.32 \\
653(5.11)\end{array}$ \\
\hline $\begin{array}{l}\mathrm{NP}-\mathrm{ZnPc}(\mathrm{TAP})_{4}- \\
\mathrm{Ptx}\end{array}$ & $\begin{array}{l}\Phi_{\Delta}^{\mathrm{a}} \\
\lambda_{\mathrm{m} / \mathrm{nm}\left(\log _{\mathrm{c}}\right)}\end{array}$ & $\begin{array}{l}0.55 \\
683(5.47)\end{array}$ & $\begin{array}{l}0.55 \\
683(5.44)\end{array}$ & $\begin{array}{l}0.52 \\
683(5.37)\end{array}$ & $\begin{array}{l}0.48 \\
684(5.33)\end{array}$ & $\begin{array}{l}0.47 \\
686(5.32)\end{array}$ & $\begin{array}{l}0.45 \\
686(5.31)\end{array}$ & $\begin{array}{l}0.43 \\
686(5.31)\end{array}$ & $\begin{array}{l}0.42 \\
686(5.31)\end{array}$ & $\begin{array}{l}0.42 \\
686(5.31)\end{array}$ \\
\hline
\end{tabular}

Note: ${ }^{a}$ Determined using DPBF as chemical quencher and methylene blue in $\mathrm{D}_{2} \mathrm{O}$ as the reference $\left(\Phi_{-}=0.52\right)$.

Abbreviations: NP, nanoparticle; ZnPc, zinc phthalocyanine; Ptx, paclitaxel; DPBF, diphenylisobenzofuran. 


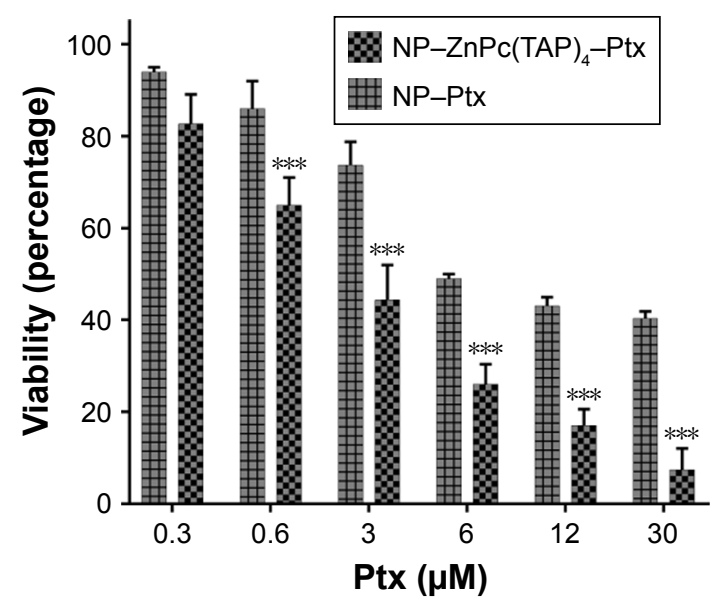

Figure S2 Cytotoxicity of NP-ZnPc(TAP) - Ptx and NP-Ptx for HI299 cells at Ptx concentrations of $0.3 \mu \mathrm{M}, 0.6 \mu \mathrm{M}, 3 \mu \mathrm{M}, 6 \mu \mathrm{M}, 12 \mu \mathrm{M}$, and $30 \mu \mathrm{M}$.

Notes: After 8,000 adherent cells in each well of 96 -well plates had absorbed NP-ZnPc(TAP) $)_{4}-\mathrm{Ptx}$ or NP-Ptx for 24 hours, cells were illuminated with light fluence of $1.5 \mathrm{~J} / \mathrm{sm}^{2}$ for I minute. Another 24 hours later, viable cells were checked by MTT. NP-ZnPc(TAP) - Ptx had enhanced cytotoxicity over NP-Ptx, which further demonstrated the synergistic antitumor effect. $* * * P<0.001$.

Abbreviations: NP, nanoparticle; ZnPc, zinc phthalocyanine; Ptx, paclitaxel.

International Journal of Nanomedicine

\section{Publish your work in this journal}

The International Journal of Nanomedicine is an international, peerreviewed journal focusing on the application of nanotechnology in diagnostics, therapeutics, and drug delivery systems throughou the biomedical field. This journal is indexed on PubMed Central, MedLine, CAS, SciSearch $®$, Current Contents $\AA /$ Clinical Medicine,
Journal Citation Reports/Science Edition, EMBase, Scopus and the Elsevier Bibliographic databases. The manuscript management system is completely online and includes a very quick and fair peer-review system, which is all easy to use. Visit http://www.dovepress.com/ testimonials.php to read real quotes from published authors. 